INTERNATIONAL JOURNAL OF SYSTEMATIC BACTERIOLOGY

Vol. 16, No. 4 October 1966 pp. 383-415

\title{
FERMENTATION PATTERNS OF SOME CLOSTRIDIUM SPECIES ${ }^{1}$
}

W. E. C. Moore, Elizabeth P. Cato and Lillian V. Holdeman

Department of Veterinary Science

Virginia Agricultural Experiment Station

Virginia Polytechnic Institute, Blacksburg

SUMMARY. The present study of the fermentation characteristics of 20 species of clostridia has shown that the relative proportions and concentrations of the acids and alcohols produced by these cultures may be very useful in their characterization and identification. The chromatographic methods described a re rapid and the patterns are highly reproducible among strains of the same species.

\section{MATERIALS AND METHODS}

At least three strains of each species have been compared. Reference strains were used in most cases; previously characterized diagnostic cultures were used when three reference strains of one species were not available. Reference cultures were obtained from Drs. L. DS. Smith, A-R. Prévot, A. Johannsen, M. F. Eklund, G. Hobbs, C. E. Dolman, K. F. Meyer, L. S. McClung, the American Type Culture Collection, and the Anaerobe Laboratory of the Communicable Disease Center. The strains previouslywere identified by different investigators and had been stored under different conditions for varying lengths of time. Except for cultures of $\underline{C}$. butyricum (type species), at least one strain of each species was isolated from clinical material. We have used as reference strains only those organisms with characteristics which closely conform to the published descriptions. For those cultures designated "SL" (so labeled), we have not completed the entire list of the tests which assure that the diagnostic characteristics of these strains conform to those in the published descriptions (Table 1).

The authors wish to acknowledge the support of this work by the National Institutes of Health, Institute of Allergy and Infectious Disease. Received for publication 6/13/66. 


\begin{tabular}{|c|c|c|c|c|c|c|c|}
\hline $\begin{array}{l}\text { spectes } \\
\text { strain number (source) }\end{array}$ & 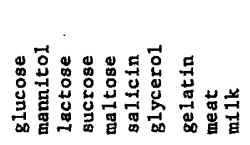 & 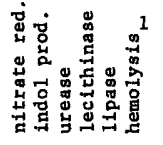 & 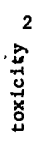 & 莣 & $\begin{array}{c}\text { fermentation } \\
\text { products }\end{array}$ & conments & $\begin{array}{l}\text { see } \\
\text { fig } \\
\text { \# }\end{array}$ \\
\hline $\begin{array}{l}\text { C. bifermentans } \\
2035 \text { (CDC } 258 \text { human) } \ldots \ldots \ldots \ldots \ldots \\
2036 \text { (CDC } 352 \text { foot) } \ldots \ldots \ldots \ldots \ldots \\
2012 \text { (ATCC 638) } \ldots \ldots \ldots \ldots \ldots \ldots\end{array}$ & 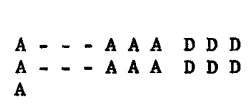 & $\begin{array}{l}-+-+-+^{r} \\
-+-+-t^{r} \\
+-+-t^{h}\end{array}$ & $=$ & $\begin{array}{l}0, \mathrm{ST} \\
0, \mathrm{ST} \\
0, \mathrm{ST}\end{array}$ & $\begin{array}{l}\mathrm{A}, \mathrm{P}, \mathrm{IB}, \mathrm{IV} \\
\text { IC,H, } \\
\text { alcohois }\end{array}$ & $\begin{array}{l}\text { Utilizes pyruvate and, } \\
\text { to a lesser extent, } \\
\text { lactate. }\end{array}$ & 23 \\
\hline 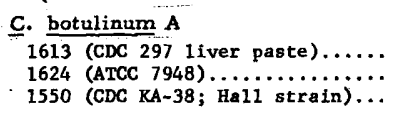 & A - - A - A $\begin{array}{ll}\text { D } & \text { D } \\
\text { D } & \text { D } \\
& \text { D }\end{array}$ & $\begin{aligned}-\cdots & +t_{h}^{r} \\
& -+t_{h} \\
& -++\end{aligned}$ & $\begin{array}{l}+* \\
+* \\
+*\end{array}$ & $\begin{array}{l}0, \mathrm{ST} \\
0, \mathrm{ST} \\
0, \mathrm{ST}\end{array}$ & $\begin{array}{l}\text { A,P,IB,B,IV } \\
\text { V,IC } \\
\text { a1cohols }\end{array}$ & $\begin{array}{l}\text { Converts pyruvate } \\
\text { and lactate. }\end{array}$ & 26 \\
\hline 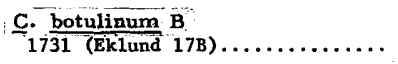 & $A A=D--$ & $\cdots+t^{h}$ & $+*$ & $0, \mathrm{ST}$ & $A, B$, butanol & $\begin{array}{l}\text { Utilizes pyruvate, } \\
\text { converts lactate. }\end{array}$ & 10 \\
\hline $\begin{array}{l}1612 \text { (CDC } 212 D \text { beans) } \ldots \ldots \ldots \ldots \\
1541 \text { (CDC KA-40; Smith A-116) } \ldots \\
1618 \text { (ATCC } 7949) \ldots \ldots \ldots \ldots \ldots \ldots\end{array}$ & 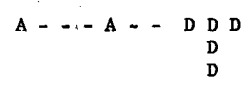 & $\begin{array}{r}-\cdots++^{r} \\
-++^{r} \\
-++^{h}\end{array}$ & $\begin{array}{l}+* \\
+* \\
+*\end{array}$ & $\begin{array}{l}0, \mathrm{ST} \\
0, \mathrm{ST} \\
0, \mathrm{ST}\end{array}$ & $\begin{array}{c}A, P, I B, B, I V \\
\text { V,IC, } \\
\text { alcohols }\end{array}$ & $\begin{array}{l}\text { Converts pyruvate and } \\
\text { lactate. }\end{array}$ & $\begin{array}{r}26 \\
\text { and } \\
27\end{array}$ \\
\hline $\begin{array}{l}\text { C. botulinum } \\
1542 \text { (CDC } K A \\
\left.\text { (1626-SL) (Prevot; G G Gunnison } C_{a}\right) \ldots\end{array}$ & D - & $\begin{array}{l}-++^{r} \\
-+t^{h}\end{array}$ & $+*$ & $\begin{array}{l}0, \mathrm{ST} \\
0, \mathrm{ST}\end{array}$ & $A, P, B$ & $\begin{array}{l}\text { Converts lactate, pri- } \\
\text { marily to propionate. } \\
\text { Converts pyruvate. }\end{array}$ & 16 \\
\hline $\begin{array}{l}\text { C. botulinum } \\
1543(\mathrm{CDC} \text { KA-39; } \\
1615 \text { (ATCC } 9633) \ldots \ldots \ldots \ldots \ldots \ldots\end{array}$ & & $\begin{array}{l}-++^{r} \\
-++^{h}\end{array}$ & $\begin{array}{l}+* \\
+*\end{array}$ & $\begin{array}{l}\text { o,sT } \\
\text { o,sT }\end{array}$ & $A, P, B$ & $\begin{array}{l}\text { Converts lactate, pri- } \\
\text { marily to propionate. } \\
\text { Converts pyruvate. }\end{array}$ & 16 \\
\hline
\end{tabular}




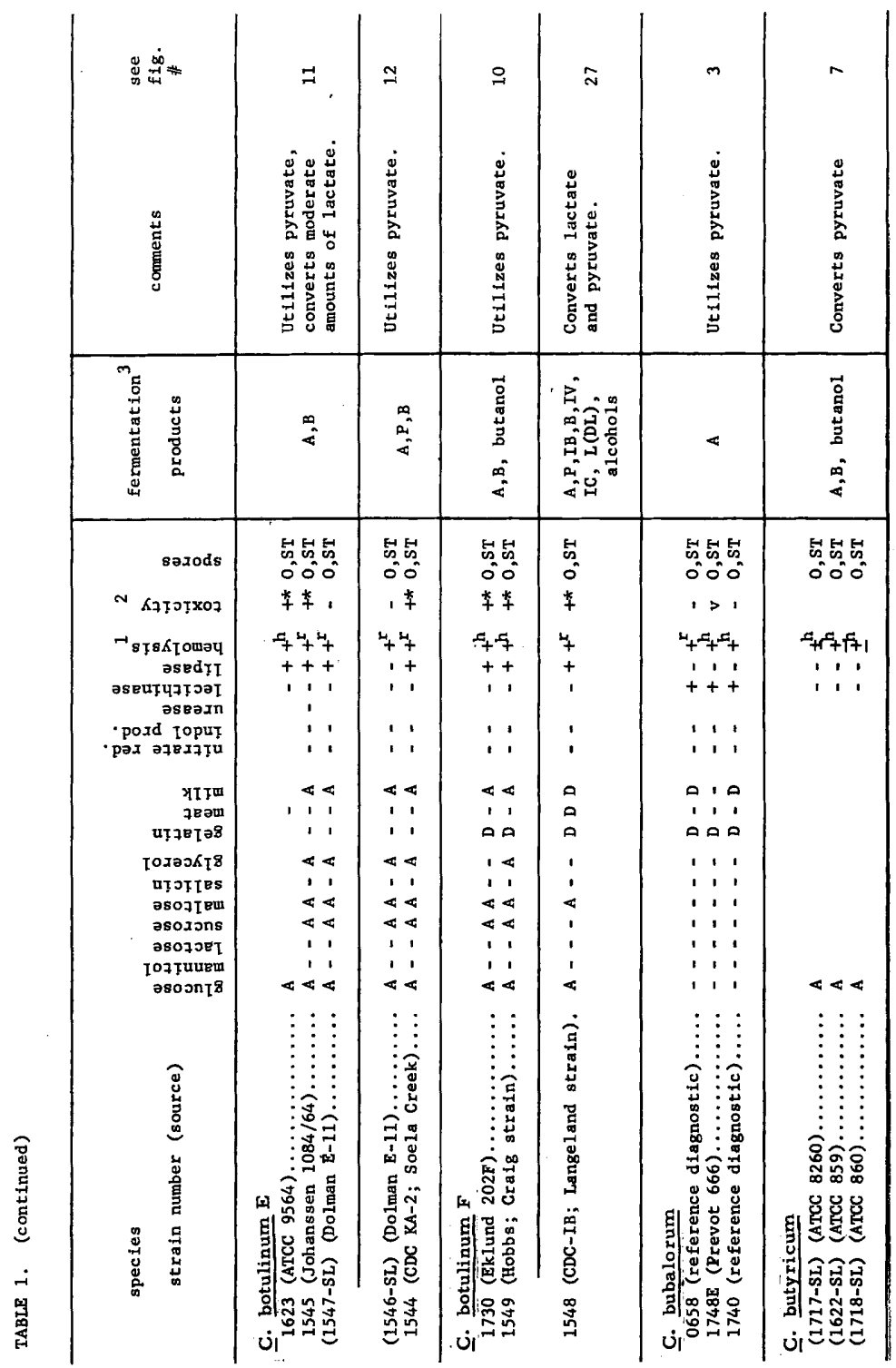




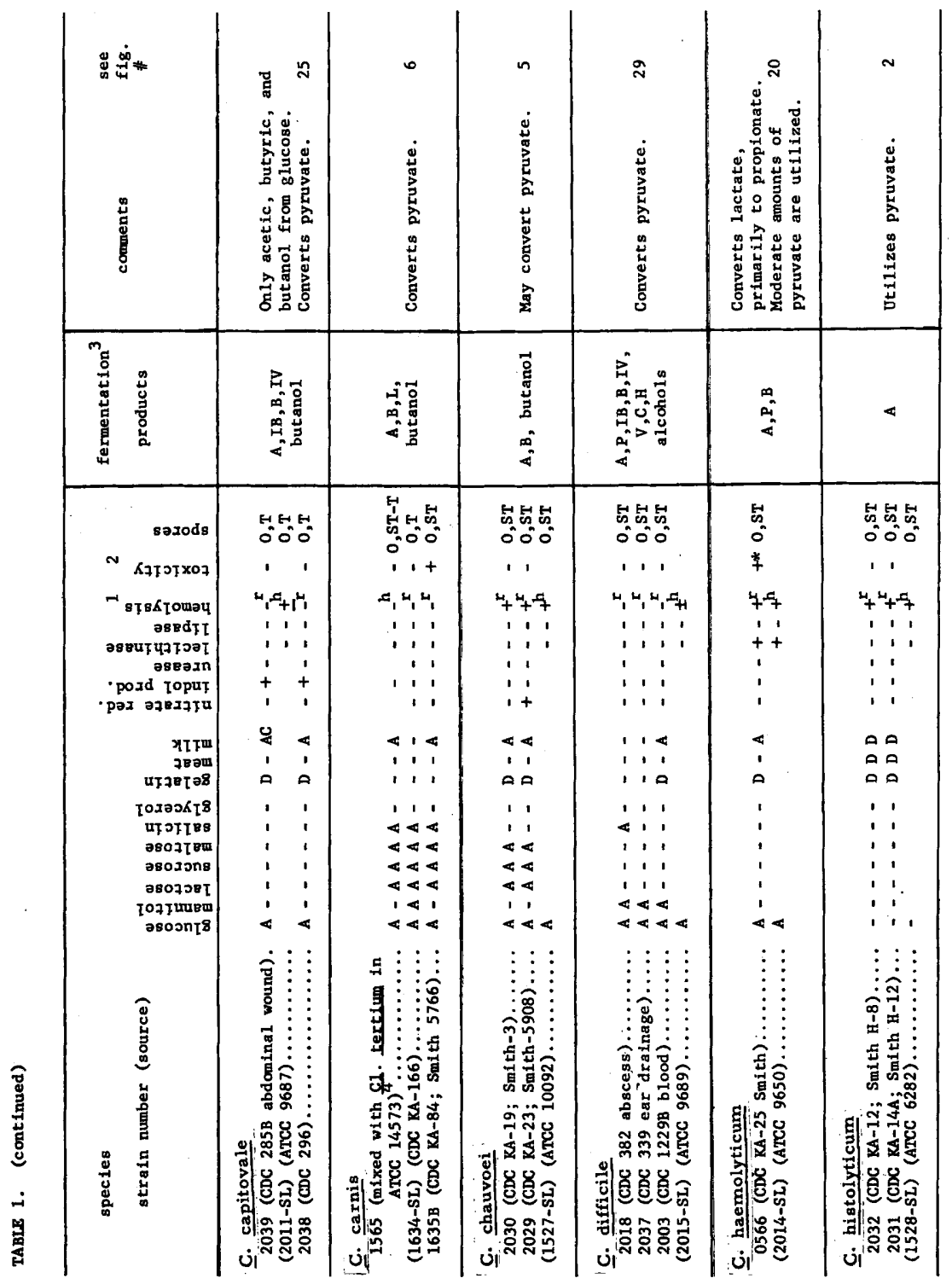




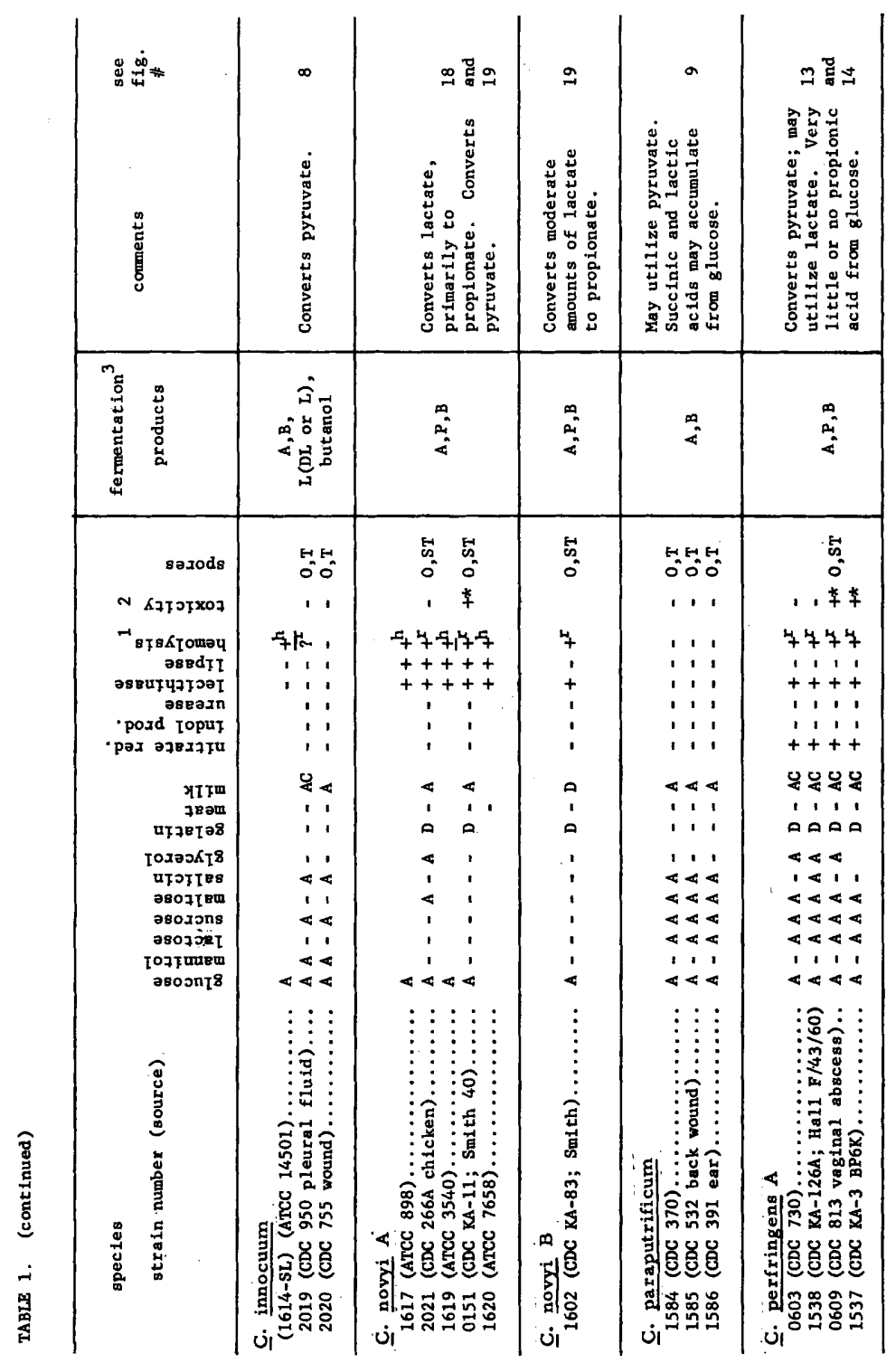




\begin{tabular}{|c|c|c|c|c|c|}
\hline 导 & 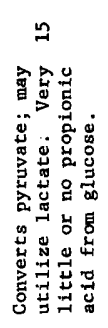 & 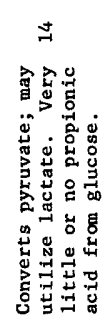 & 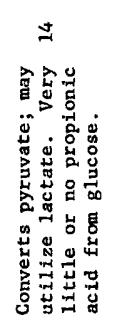 & 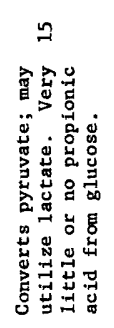 & 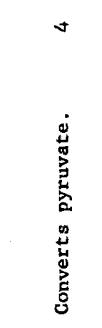 \\
\hline 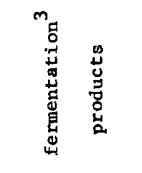 & 告 & 然 & $\overbrace{}^{\infty}$ & מُ & 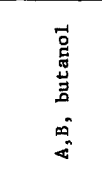 \\
\hline $\begin{array}{l}\text { saxods } \\
N \quad \text { N }\end{array}$ & $*$ & & & & 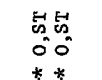 \\
\hline 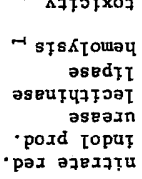 & $\begin{array}{l}+ \\
+ \\
+ \\
+ \\
1 \\
+\end{array}$ & $\begin{array}{l}7 \\
4 \\
+ \\
1 \\
+ \\
1 \\
+\end{array}$ & $\begin{array}{l}+ \\
7 \\
1 \\
+ \\
1 \\
+\end{array}$ & $\begin{array}{l}7+ \\
74 \\
17 \\
++ \\
10 \\
++\end{array}$ & $\begin{array}{l}5+7 \\
4+7 \\
+75 \\
1: 1 \\
1: 1 \\
1:\end{array}$ \\
\hline 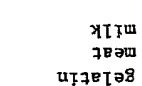 & $\begin{array}{l}0 \\
0\end{array}$ & $\begin{array}{l}\dot{4} \\
\dot{1} \\
\dot{a}\end{array}$ & í & $A D$ & $\begin{array}{l}y 0 \\
11 \\
0\end{array}$ \\
\hline 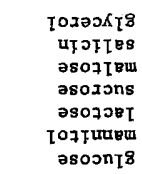 & $\begin{array}{l}4 \\
4 \\
4\end{array}$ & $\begin{array}{l}1 \\
4 \\
4 \\
4 \\
4\end{array}$ & 4 & $\begin{array}{l}44 \\
44 \\
44 \\
14 \\
44\end{array}$ & $\begin{array}{l}11 \\
44 \\
44 \\
11 \\
44 \\
44<\end{array}$ \\
\hline 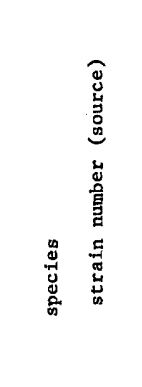 & 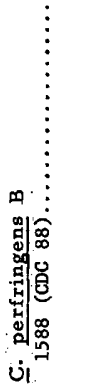 & 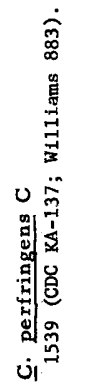 & 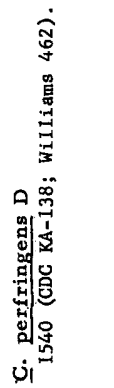 & 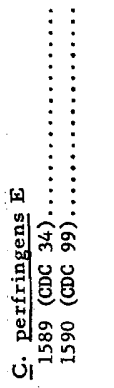 & 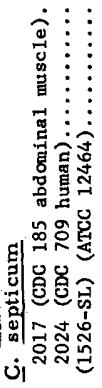 \\
\hline
\end{tabular}




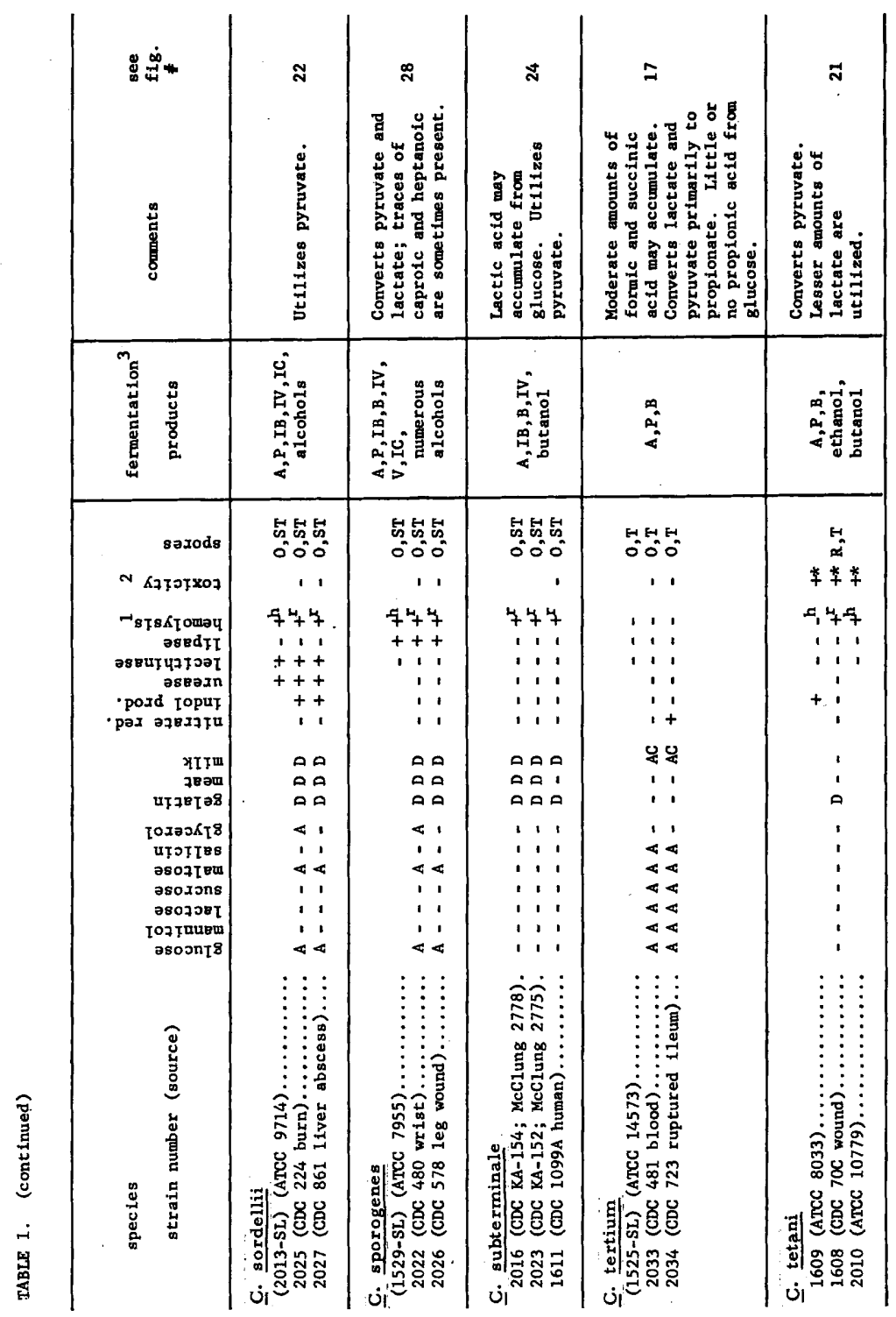


EXPLANATION FOR TABLE I AND TABLE 1 CONTINUED

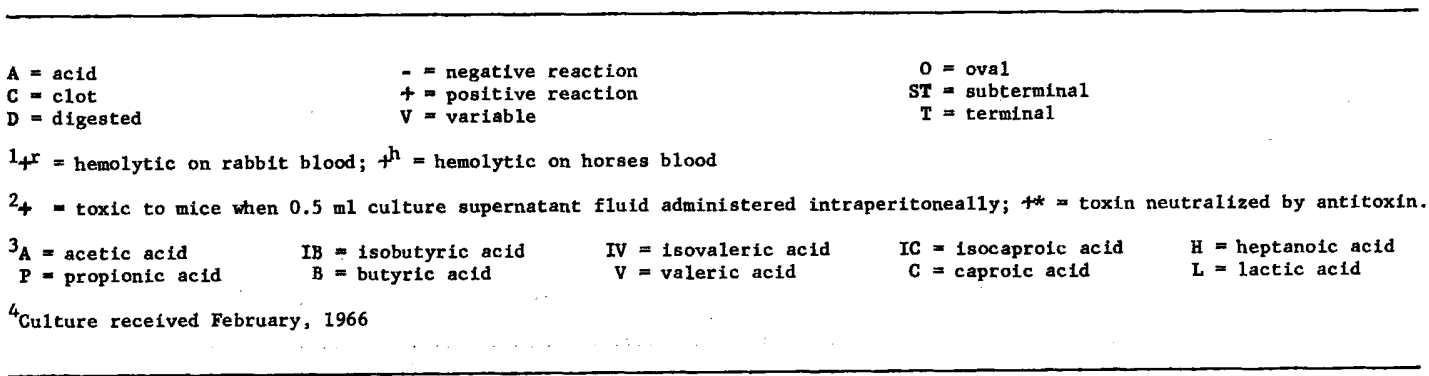


Toxin neutralization tests were used to confirm the identity of all toxic cultures. Antitoxin for these tests was prepared at the Wellcome Research Laboratories and at the Communicable Disease Center. Indol was detected with Erlich's reagent after xylene extraction of tryptophane or chopped meat media cultures.

Acid and alcoholic fermentation products were analyzed from 3-week cultures in four media (Moore and Cato, 1965): 1) PY (2\% peptone, $1 \%$ yeast extract), 2) PYG (PY plus $1 \%$ glucose), 3) LACT (PY plus sodium lactate - $0.95 \mathrm{ml} 85 \%$ lactic acid/100 ml), and 4) PYRU (PY plus sodium pyruvate $=0.88 \mathrm{ml}$ pyruvic acid/100 ml). Four to five ml media, prepared by the method of Moore and Cato (1965), were inoculated with about $0.04 \mathrm{ml}$ of an actively growing culture and incubated at $37^{\circ} \mathrm{C}$. After incubation for three weeks, cultures were acidified to $\mathrm{pH} 2$ with a solution of $50 \% \mathrm{H}_{2} \mathrm{SO}_{4}$ (equal parts $\mathrm{v} / \mathrm{v}$ distilled water and concentrated $\mathrm{H}_{2} \mathrm{SO}_{4}$ ). One milliliter portions were chromatographed according to the procedures of Bruno and Moore (1962) on a temperaturecontrolled silicic acid liquid column. These were developed in 20-30 minutes. On this column, isomers of butyric, valeric, and caproic acids appear as mixtures in one or two peaks. Propionic, acetic, formic, succinic, and lactic acids are resolved, but pyruvic acid usually is not separated from formic acid. Improved separation of all acids can be obtained if the column is developed more slowly. However, results obtained in our routine manner have proved to be satisfactory for our purposes.

The 3 to $4 \mathrm{mls}$ of the remainder of the acidified culture were extracted for analysis by gas chromatography. The cultures were extracted with $1 \mathrm{ml}$ of ethyl ether by shaking vigorously for about one minute. The resultant emulsion was separated by brief centrifugation and the ether layer transferred to a small tube with a Pasteur pipette. Anhydrous $\mathrm{MgSO}_{4}$ (approximately $60 \%$ powder to ether extract, by volume) was added to each extract and shaken briefly to dry the ether. Fourteen microliters of the ether extract samples were analyzed by gas chromatography on the Beckman GC-2A using a stainless steel column (1/4 inch O. D. , 6 feet long) packed with Resoflex LAC-1-R-296, standard concentration(P), (Burrell Corporation, Pitts burgh, Pennsylvania). The chromatograph was operated at $110^{\circ} \mathrm{C}$ under 32 pounds pressure of helium with a thermal conductivity detector at 200 milliamps. We continue to use a thermal conductivity detector, even though a flame ionization detector is more 
sensitive to carbon compounds and is insensitive to water, because several investigators have found that nearly all columns on which large amounts of water are placed retain portions of the acetic acid from each sample. The trapped acetic acid is eluted with succeeding samples, giving false positive results. The 2- to 6 -carbon alcohols and acetic, propionic, and the isomers of 4- to 8-carbon acids are separated on this gas column. The approximate retention times (in minutes) of the compounds 'routinely observed are: ether, 0.2; ethyl alcohol, 0.6-0.7; propyl alcohol, 0.8; isobutyl alcohol, 1.2; butyl alcohol, 1. 3; water, 1.4; isoamyl alcohol, 1. 6; amyl alcohol, 1.9; hexanol, 2. 6; acetic acid, 3.4; propionic acid, 4.8; isobutyric acid, 5.6; butyric acid, 7.0; isovaleric acid, 8. 3; valeric acid, 11.3 ; caproic acid, 18. 6; heptanoic acid, 24.0; and caprylic acid, 45.2. After continued use of the column, retention times generally decrease. The packed columns have a useful life of about 1000 samples.

Results obtained with silicic acid liquid column chromatography are quantitative whereas those obtained with gas column chromatography are quantitative only when the areas of peaks produced by the same compounds are compared, but not when areas produced by different compounds are compared. In general, with gas chromatography relatively larger peaks are produced, per unit value, by compounds having higher molecular weights than by those with lower molecular weights. The compounds separated by gas chromatography are identified by comparison with standard known compounds and by co-chromatography.

Comparison of the results of the two columns has indicated, in some cases, that minor amounts of a nonacidic compound may interfere with the propionic acid peak in the gas column and that certain aldehydes and ketones may interfere with the identification of alcohols under our operating conditions.

\section{RESULTS AND DISCUSSION}

We have found that all of the clostridia, as well as many of the non-spore-forming anaerobic bacteria, produce welldefined fermentation patterns (Moore and Cato, 1965). There are several (at least 11) major fermentation patterns. The same fermentation pattern may be produced by several species which otherwise appear to be unrelated. Fermentation patterns within each species are remarkably similar, even relative proportions of minor products. 
The 20 species of clostridia can be separated by gas chromatographic analyses into eight fermentation groups described below. Some of these groups can be subdivided on the basis of the silicic acid column results or the difference in the fermentation of different substrates by different species. Pyruvate is utilized or converted by most species; some also utilize or convert lactate. Substrate is "converted" when the increase in products detected (compared with basal medium) accounts for the disappearance of the substrate; substrate is considered to be "utilized" when products detected do not account for the disappearance of the substrate.

The fermentation patterns of the 20 species of clostridia tested are shown in the following figures (1-29). The first figure shows the results of analyses of uninoculated media when tested by the two chromatographic techniques. The silicic acid liquid column results presented in subsequent figures are corrected to account for the reactions of the uninoculated media; the gas column figures are not corrected for uninoculated media values, although there is little that appears from the media blanks on the gas chromatographic results except a trace of acetic acid. The water peak (see Fig. 1) is present on most of the figures to greater or lesser degree, depending on the dryness of the sample inoculated.

These chromatographic data (Figs. 1-29) were obtained from cultures incubated for three weeks. However, we have been interested in modifying our techniques to make them more useful in diagnostic laboratories where rapid identification of organisms is desirable. Replicate tubes of media were inoculated and fermentation products analyzed after incubation for 18, 42, and 66 hours, one week and three weeks. Results are presented in Figs. $30,32,34,36$. In these cultures, concentrations of fermentation products after one week are essentially the same as those at three weeks. In less than one week, the relative concentrations of several products are very different. In an attempt to obtain comparable concentrations of fermentation products in even younger cultures, calcium carbonate was added to the medium to control the pH(Figs. $31,33,35,37$ ). In such cultures of C. sporogenes, typical fermentation patterns were obtained in approximately four days. However, carbonate inhibited, but did not prevent the production of butyric acid by $\underline{\mathrm{C}}$ novyi A. The addition of carbonate did not alter the general fermentation patterns of the organisms tested to the extent that they would be assigned incorrectly to a different major fermentation group. 
Gas Chromatograph (GC) Fermentation Group 1 - acetic

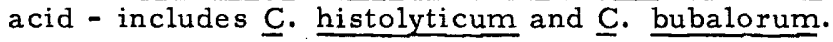

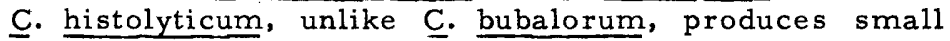
amounts of lactic acid from glucose.

C. haemolyticum, strain "historique," obtained from Dr. Prévot, also produced only acetic acid as a major product. However, . haemolyticum (historique) differs from $\underline{\text {. his- }}$ tolyticum, as well as from other reference strains of $\mathrm{C}$. haemolyticum, in several other characteristics as noted by Smith (1953).

GC Fermentation Group 2 - acetic and butyric acids - includes C. septicum; C. chauvoei; C. carnis; C. innocuum; C. paraputrificum; nonproteolytic strains of $\mathrm{C}$. botulinum types $B, E, F$; and $C$. butyricum. The nonproteolytic strains of $\mathrm{C}$. botulinum $\mathrm{B}$ and $\mathrm{E}$ are the only organisms in this group which convert moderate amounts of lactate. C. paraputrificum differs from the others in that no butyric acid is detected from growth in pyruvate medium. C. innocuum and $\underline{C}$. carnis produce lactic acid in addition to acetic and butyric.

GC Fermentation Group 3 - acetic, propionic, and butyric acids - includes $C$. perfringens $A, B, C, D, E$ and $C$. botulinum E. This group is quite similar to the previous group. However, moderate amounts of propionic acid are produced by all strains in most media. C. butyricum, in the previous group, appears to be intermediate between the se groups in that small amounts of propionic acid are produced from some media. The strains of $\underline{C}$. perfringens all produce large amounts of butyric acid from glucose, whereas the cultures of $\underline{C}$. botulinum type $\mathrm{E}$ do not. Strains of $\underline{C}$. botulinum type $E$ are found in this group as well as in the previous group. Two of these cultures (1546 and 1547) were from different colonies isolated on egg yolk agar from a culture labeled "non-toxic type $E$ " received from Dr. Dolman. As can be seen from Table 1, the two isolates from this culture have cultural characteristics very similar to those of the toxic strains of $\underline{\mathrm{C}}$. botulinum type E. However, one of these strains produces a pearly layer (is lipase-positive) on egg yolk agar and the other does not. Since toxin production is a major criterion for the identification of

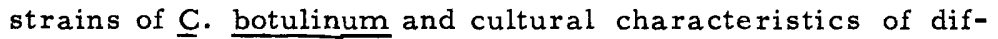
ferent types of this species frequently are not the same, the identification of "nontoxic" strains of $\mathrm{C}$. botulinum is extremely difficult. It also has been thought that all strains of 
SYSTEMATIC BACTERIOLOGY

Fermentation Pathways of some Clostridium Species

Figure page 1 of 19

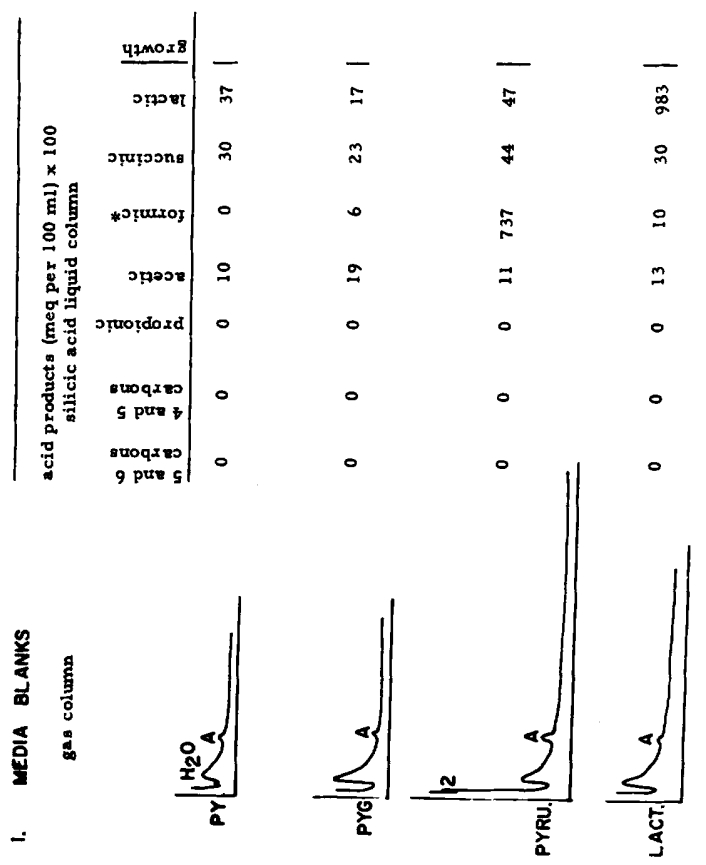


INTERNATIONAL JOURNAL Fermentation Pathways of some Clostridium Species Figure page 2 of 19
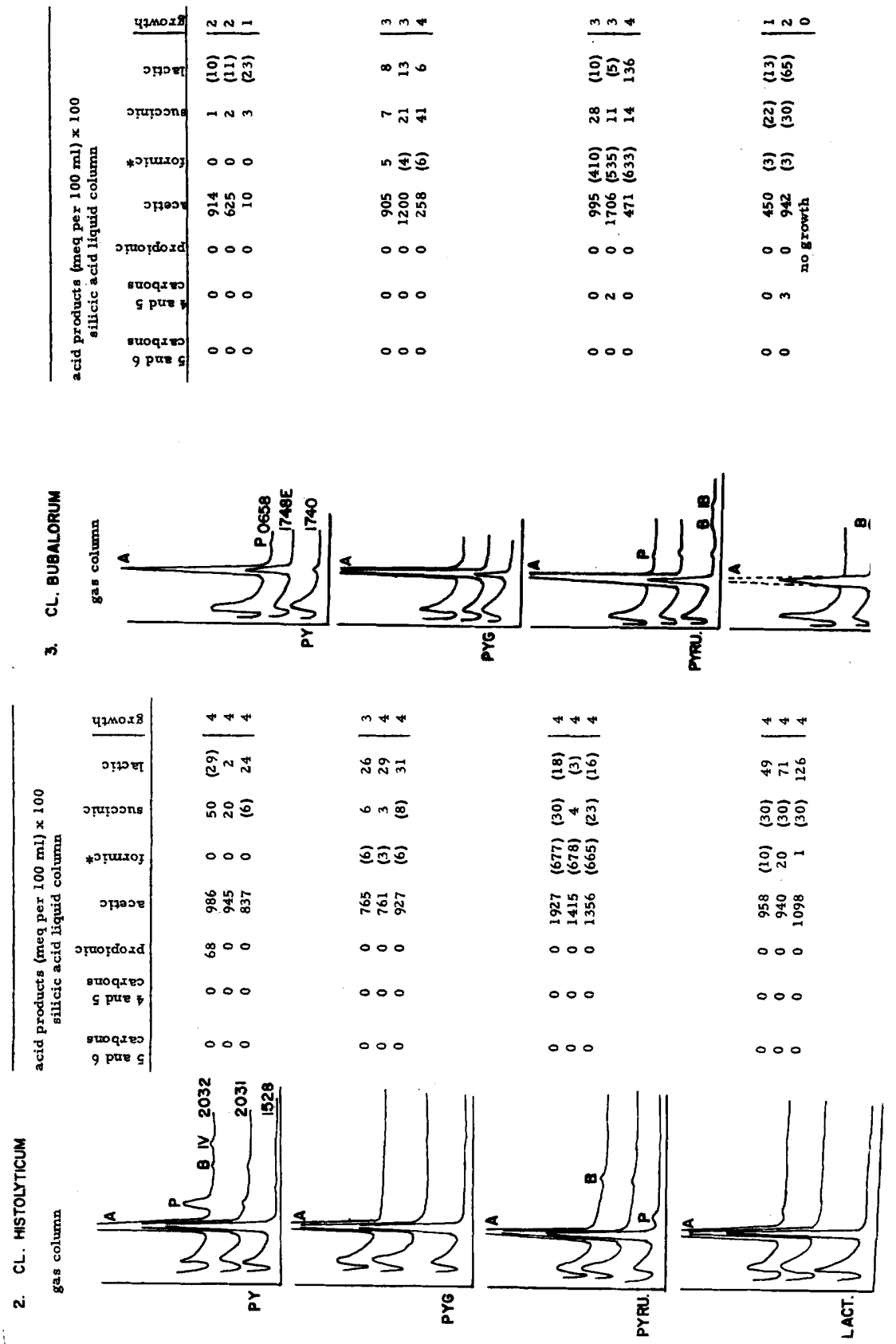

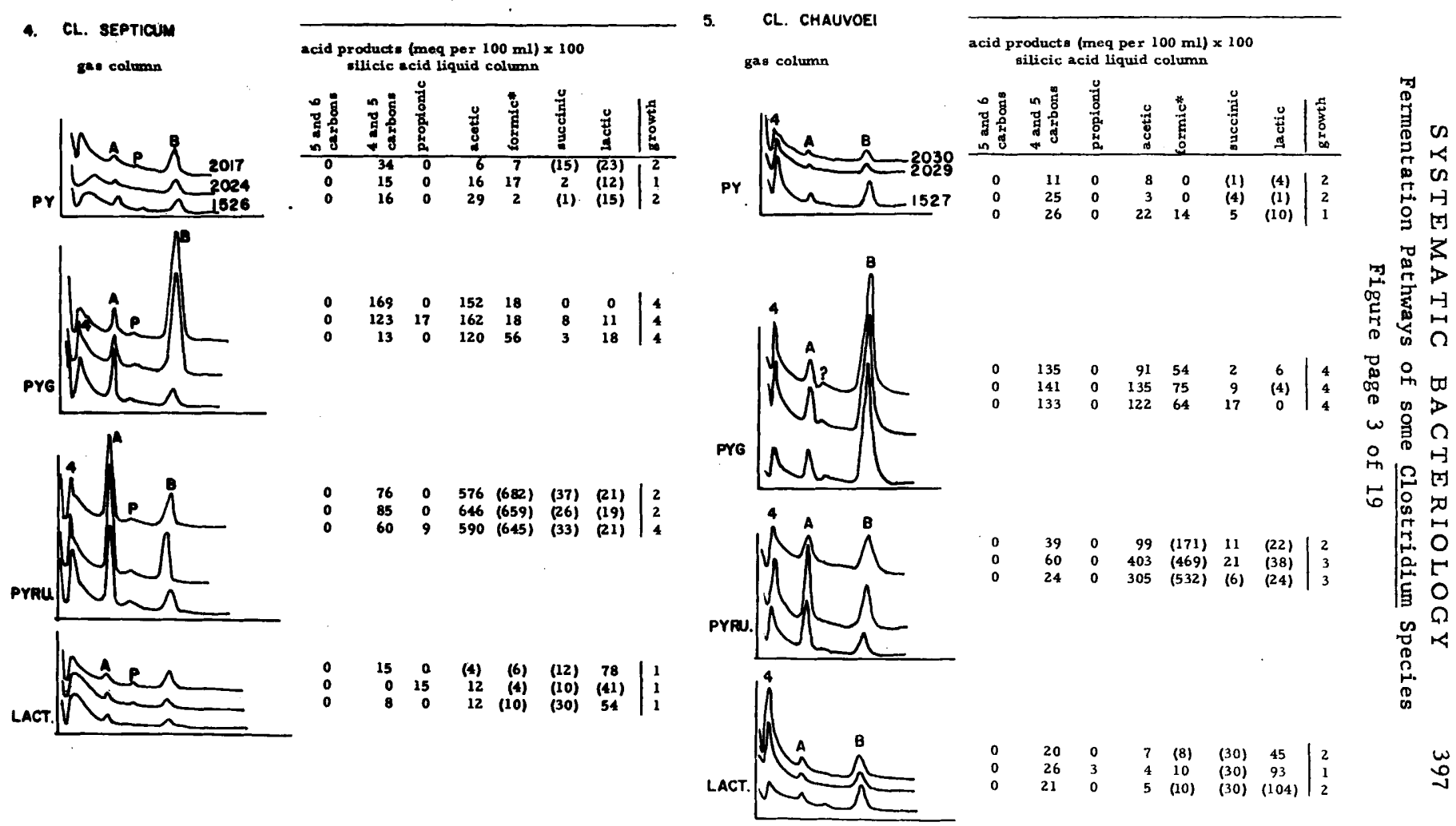

x

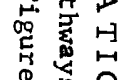

$\rightarrow \circ$

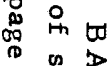

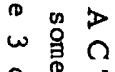

욤

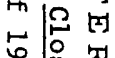

年

年

\begin{tabular}{lllrlll|l}
0 & 39 & 0 & 99 & $(171)$ & 11 & $(22)$ & 2 \\
0 & 60 & 0 & 403 & $(469)$ & 21 & $(38)$ & 3 \\
0 & 24 & 0 & 305 & $(532)$ & $(6)$ & $(24)$ & 3
\end{tabular}

居 0

क 4

ठ 


\section{CL. CARNIS}

gas column
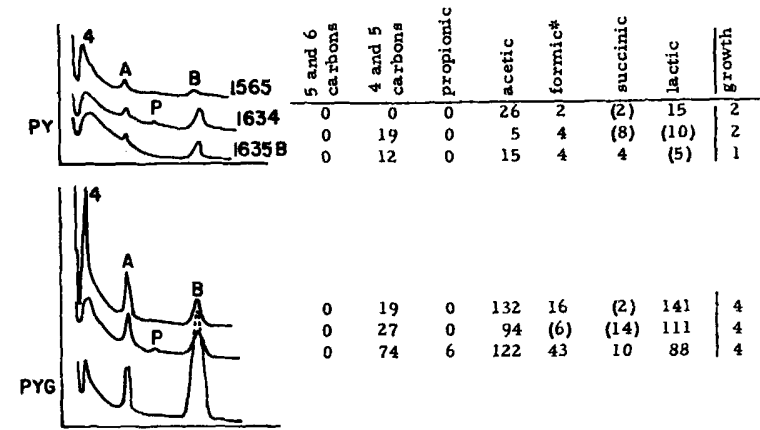

$$
\begin{array}{rrrrrrr|r}
0 & 19 & 0 & 132 & 16 & (2) & 141 & 4 \\
0 & 27 & 0 & 94 & (6) & (14) & 111 & 4 \\
0 & 74 & 6 & 122 & 43 & 10 & 88 & 4
\end{array}
$$
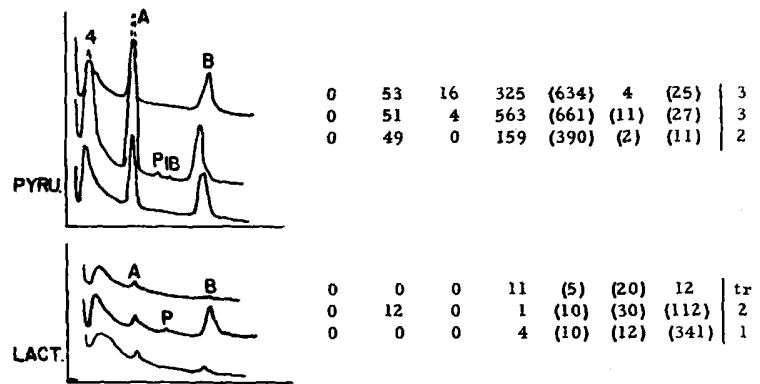

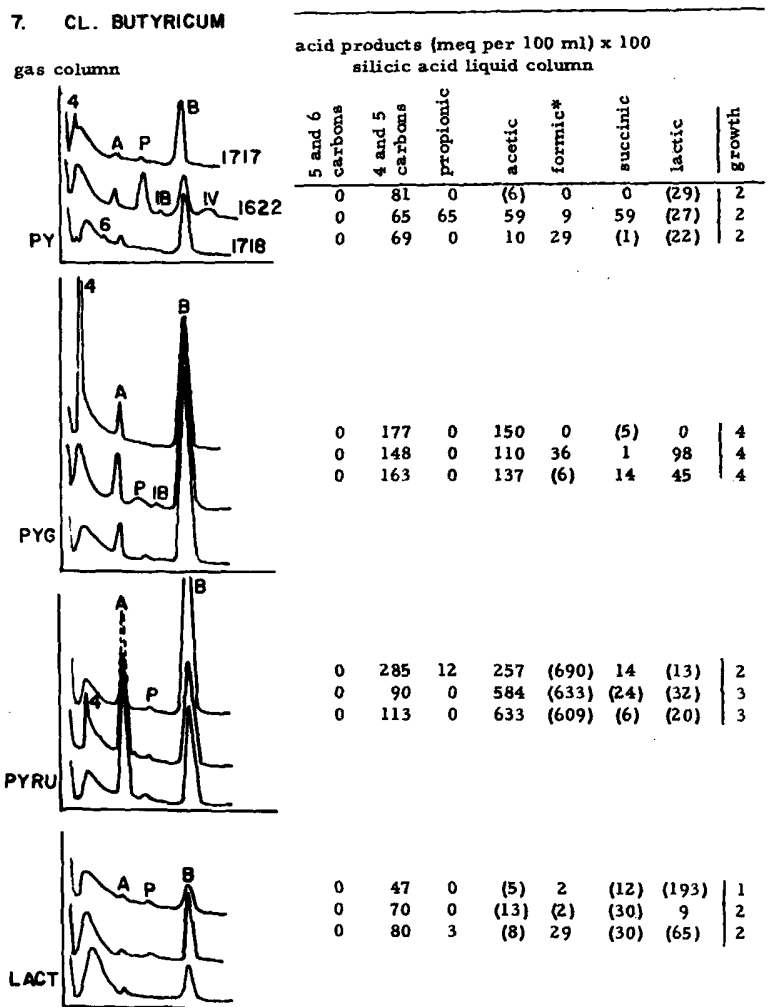

$\underset{\infty}{\omega}$

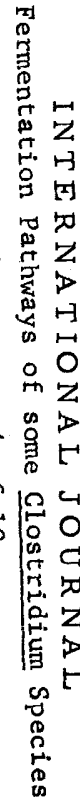



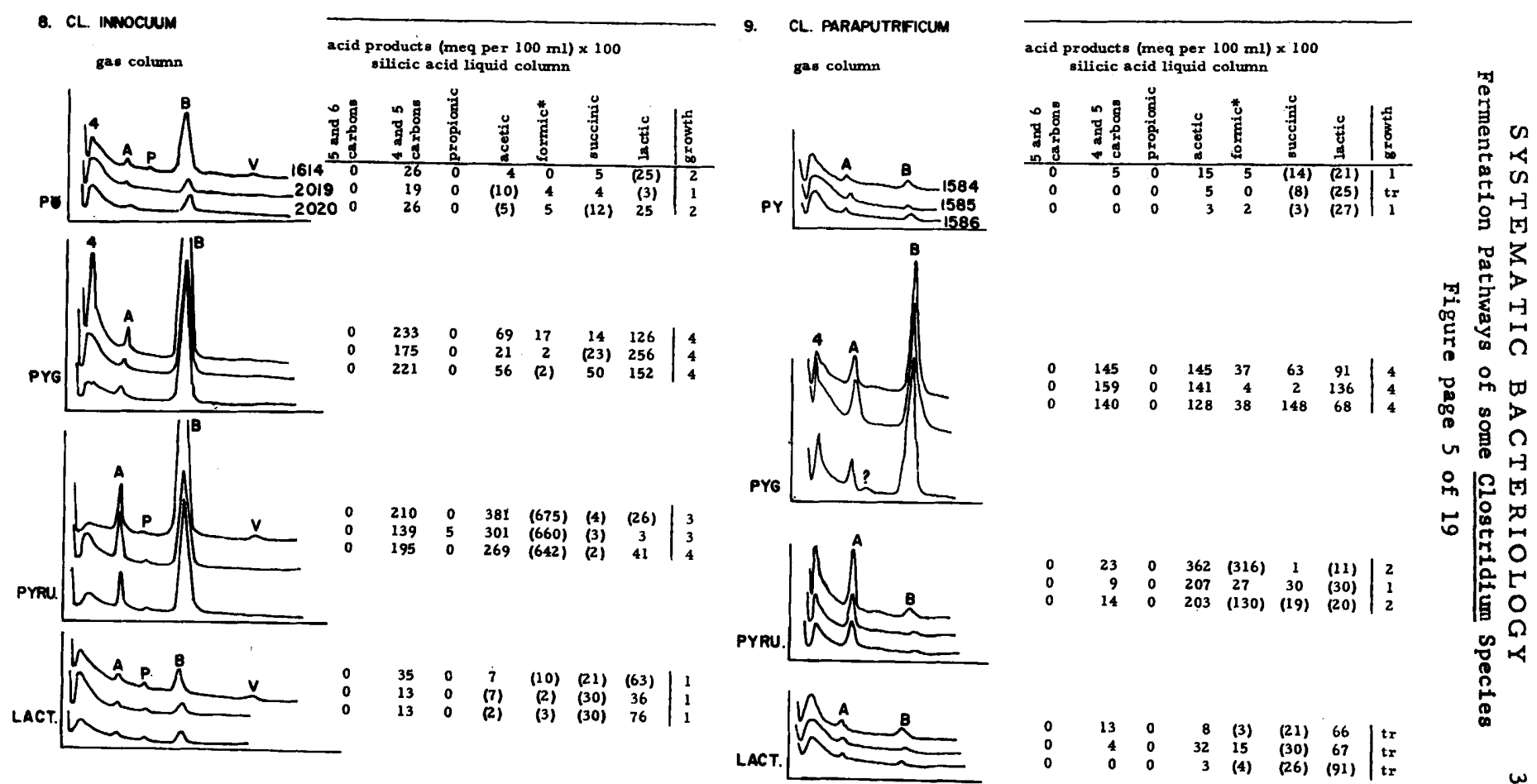


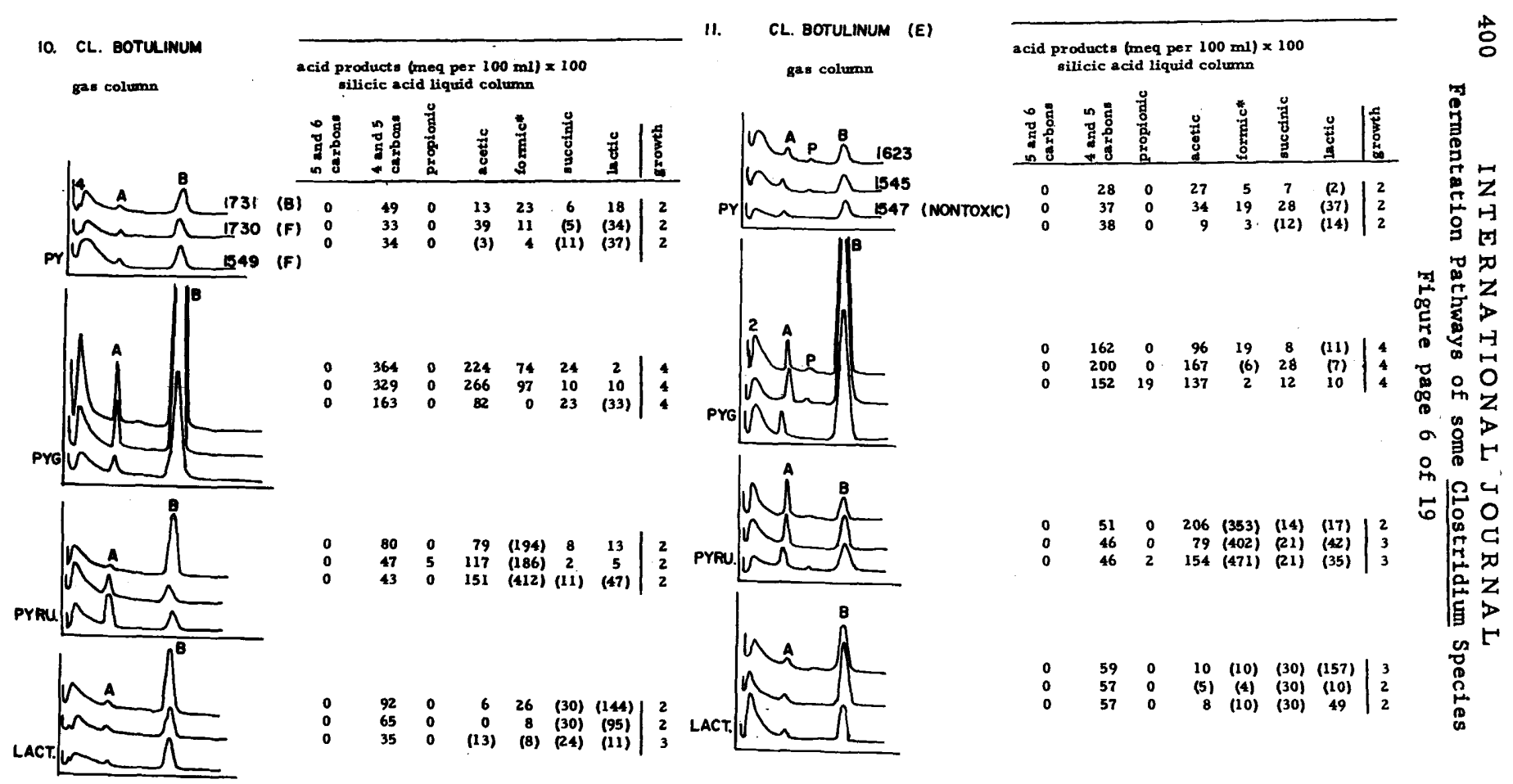


12. CL. BotUlinum (E)

gas column
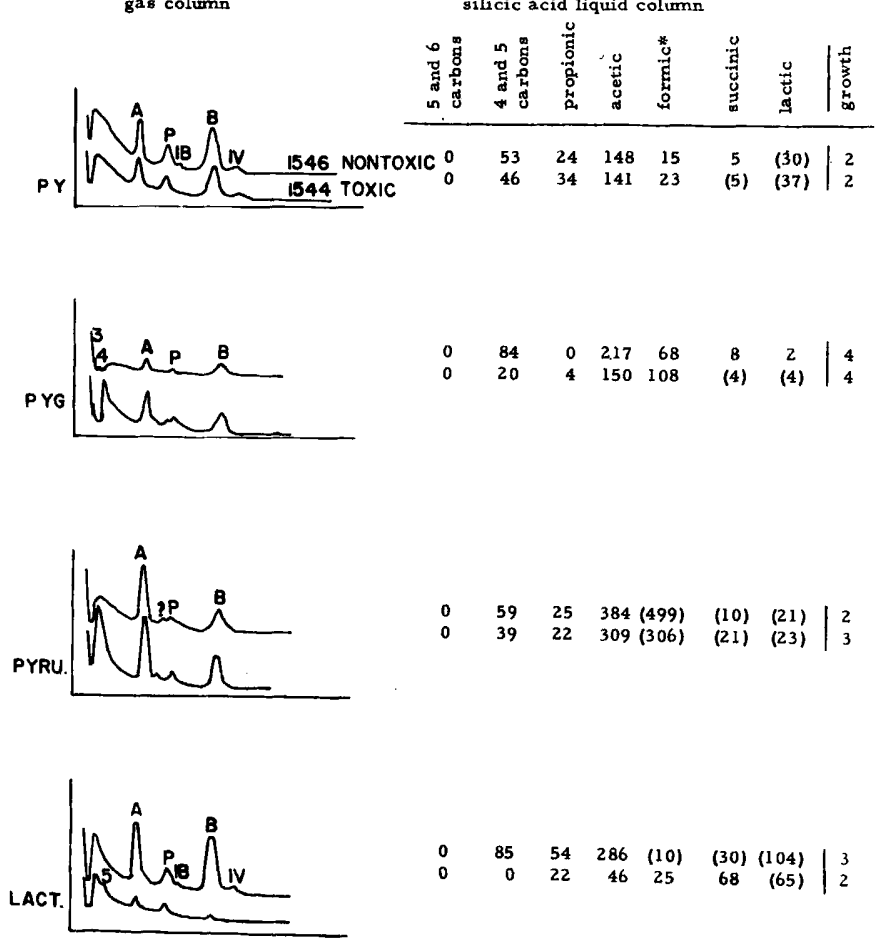

\begin{tabular}{lllllll|l}
0 & 59 & 25 & $384(499)$ & $(10)$ & $(21)$ & 2 \\
0 & 39 & 22 & $309(306)$ & $(21)$ & $(23)$ & 3
\end{tabular}

\begin{tabular}{lrrrrrr|r}
0 & 85 & 54 & 286 & $(10)$ & $(30)$ & $(104)$ & 3 \\
0 & 0 & 22 & 46 & 25 & 68 & $(65)$ & 2
\end{tabular}

\begin{tabular}{ccccccc|c}
0 & 84 & 0 & 2.17 & 68 & 8 & 2 & 4 \\
0 & 20 & 4 & 150 & 108 & $(4)$ & $(4)$ & 4
\end{tabular}
13. Cl. perfringens (A)

gas column

acid products (meq per $100 \mathrm{ml}$ ) $\times 100$ silicic acid liquid column
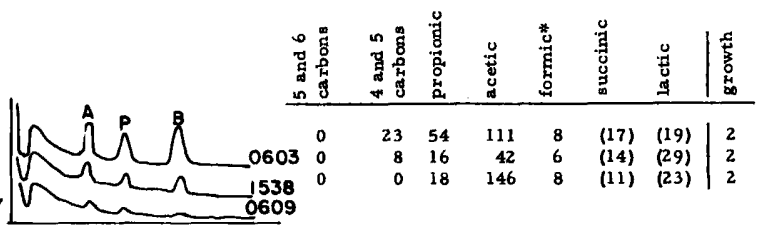

$\begin{array}{rrrrrr}8 & 16 & 42 & 6 & (14) & (29) \\ 0 & 18 & 146 & 8 & (11) & (23)\end{array}$

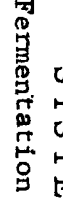

祭定

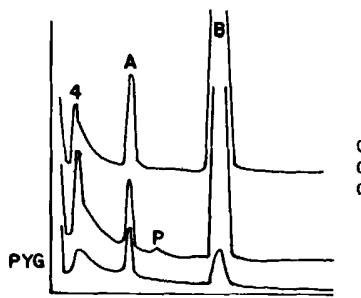

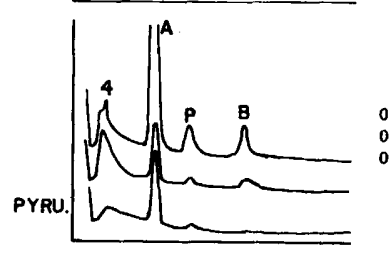

\begin{tabular}{llllll|lll}
226 & 0 & 200 & 13 & 10 & 96 & 4 & 0 & $\circ$
\end{tabular} 牟局 员 $\underbrace{0}_{0}$

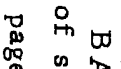
$\checkmark$ 茴 in ๒ 隹

\begin{tabular}{llllll|l|l}
52 & 32 & 839 & $(640)$ & 6 & $(2)$ & 3 & 0 \\
22 & 20 & 373 & $(517)$ & 8 & $(23)$ & 2 & 5
\end{tabular} \begin{tabular}{rrrrrc|r|r}
22 & 20 & 373 & $(517)$ & 8 & $(23)$ & 2 & F \\
0 & 28 & 725 & $(704)$ & $(14)$ & 80 & 4 &
\end{tabular} कृ 苾

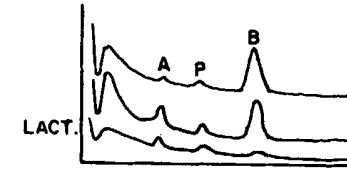




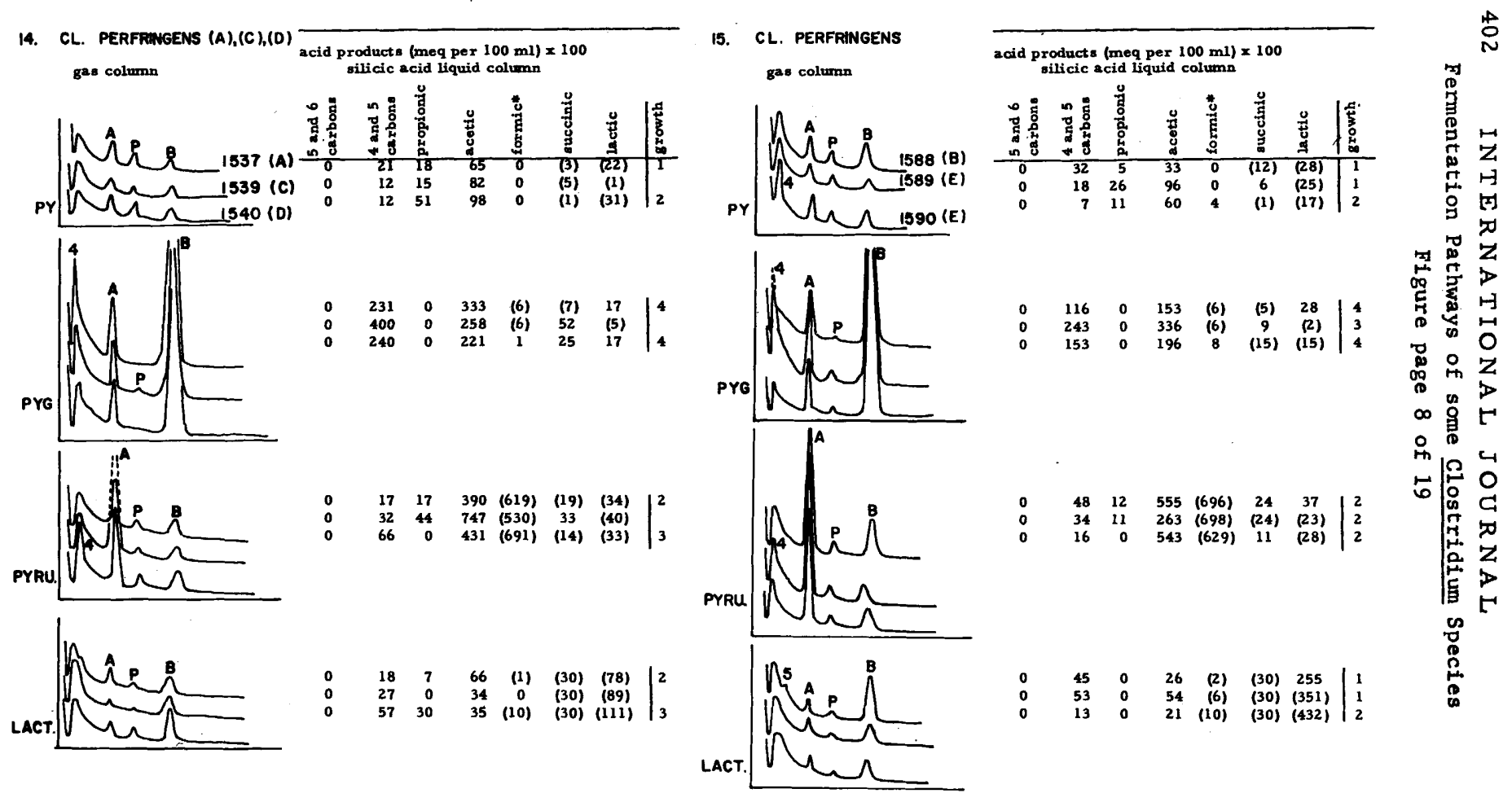




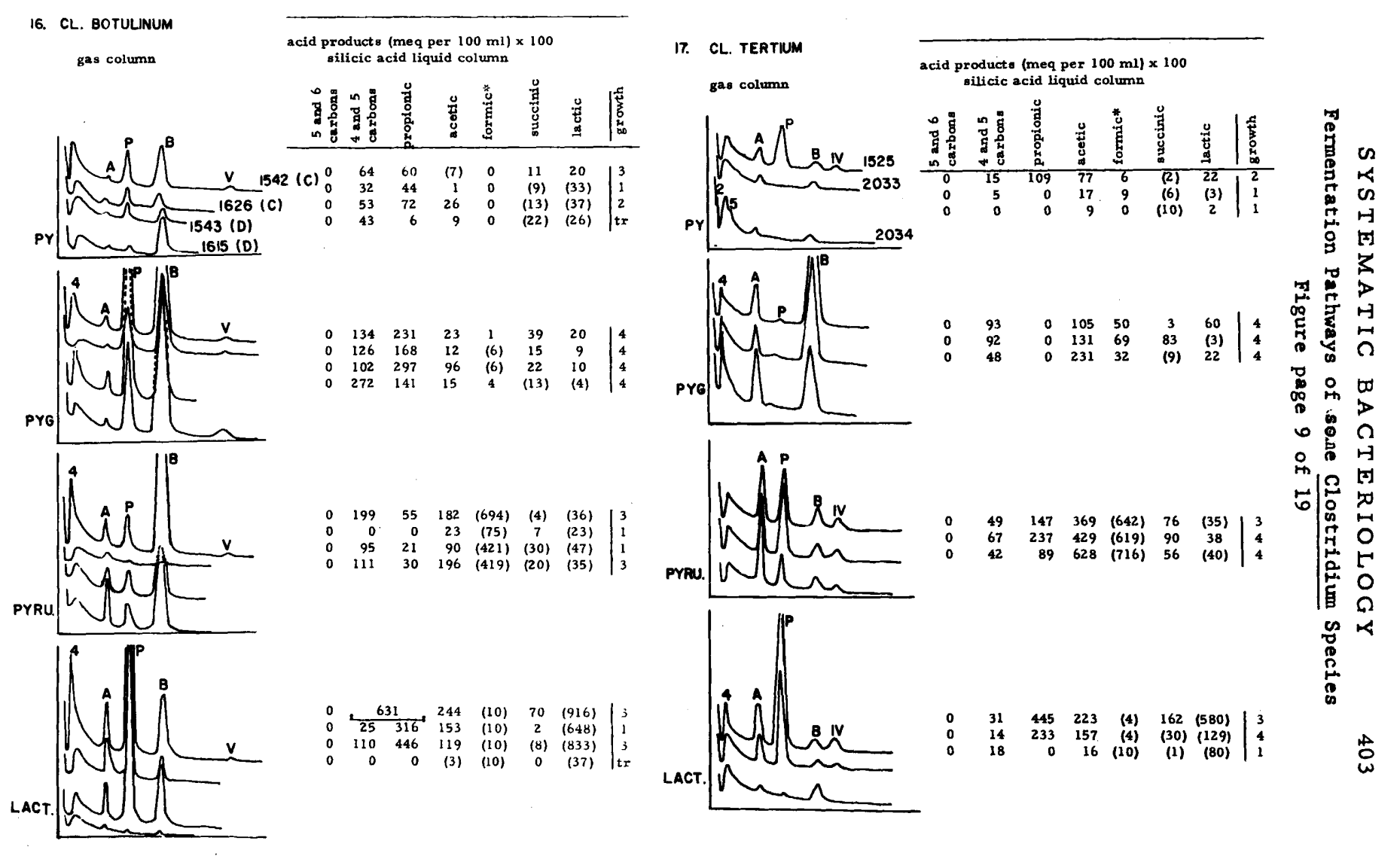




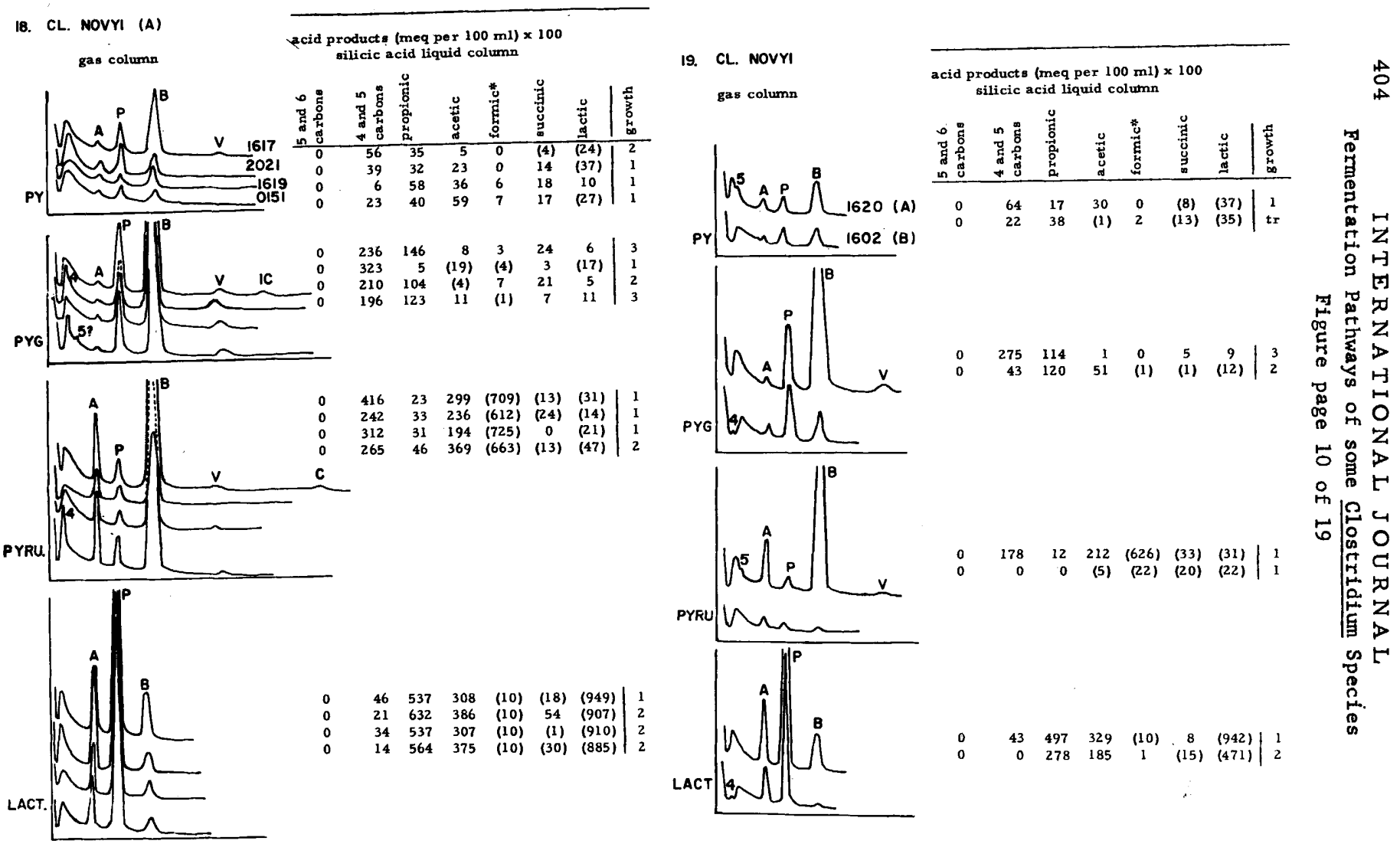



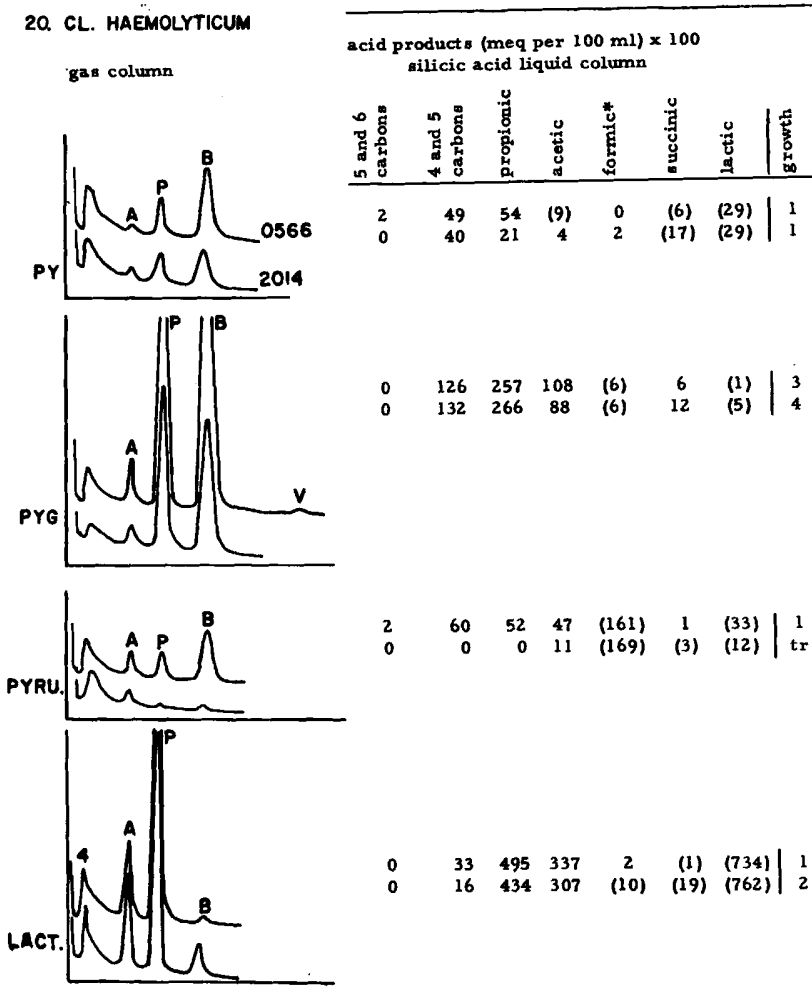

21. CL. TETANI
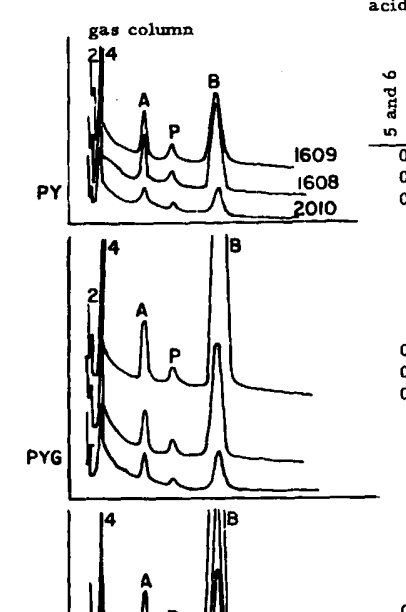

products (meq per $100 \mathrm{ml}) \times 100$ silicic acid liquid column

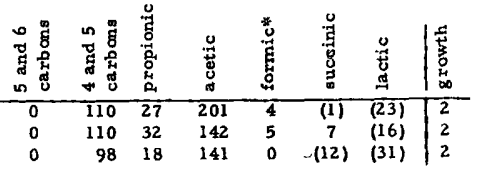

1
8
3

的

क.

马.

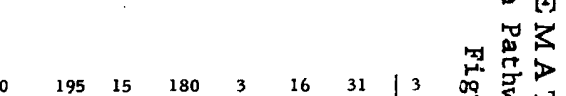

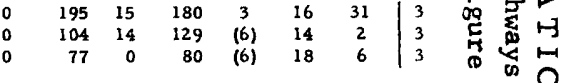

总

空

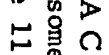

吕

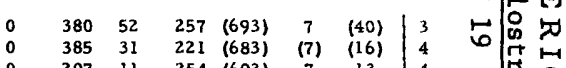

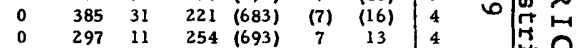

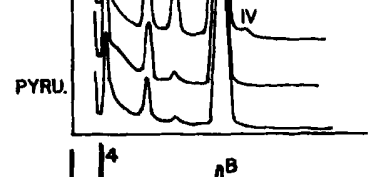

类:

留 0

क $\Omega$

$\stackrel{\infty}{\circ}$

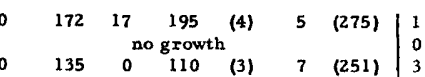




\section{CL ERERMENTANS}
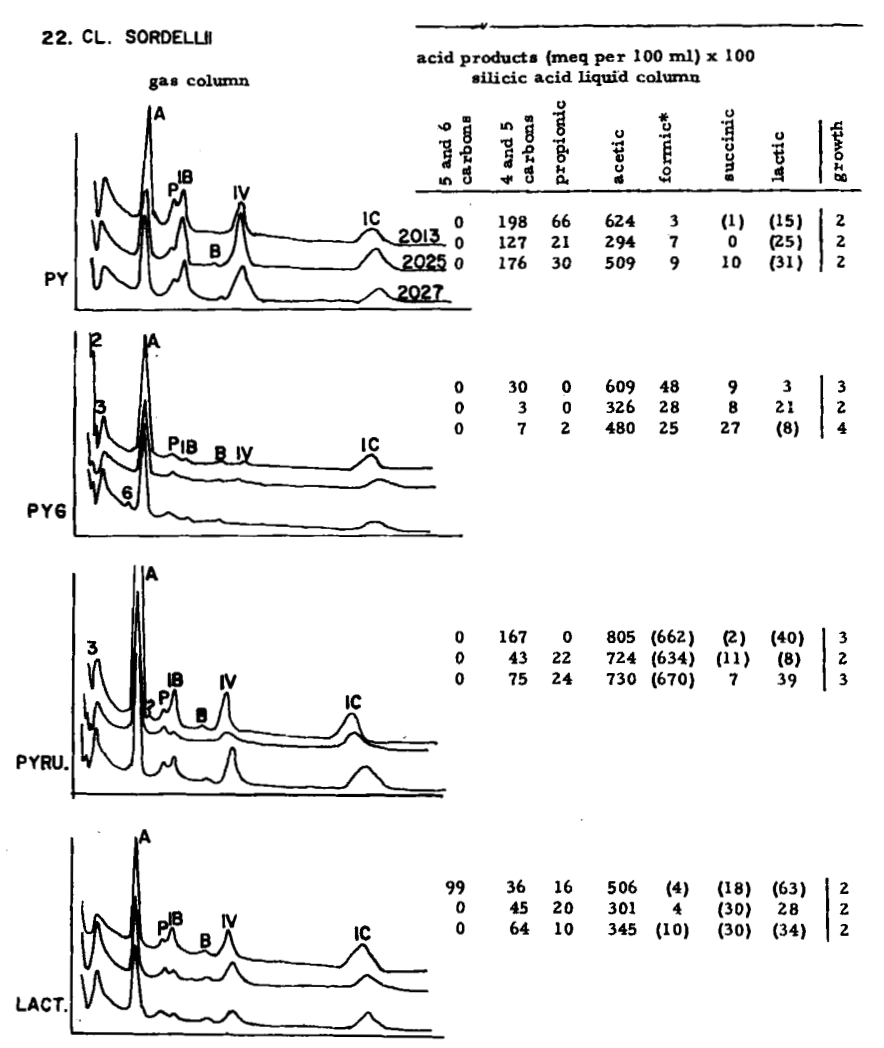

\begin{tabular}{rrrrrr|r}
30 & 0 & 609 & 48 & 9 & 3 & 3 \\
3 & 0 & 326 & 28 & 8 & 21 & 2 \\
7 & 2 & 480 & 25 & 27 & $(8)$ & 4
\end{tabular}

\begin{tabular}{rrrrrrr|r}
0 & 167 & 0 & 805 & $(662)$ & $(2)$ & $(40)$ & 3 \\
0 & 43 & 22 & 724 & $(634)$ & (11) & $(8)$ & 2
\end{tabular}

\begin{tabular}{lllllll|l}
0 & 43 & 22 & 724 & $(634)$ & $(11)$ & $(8)$ & 3 \\
2 \\
0 & 75 & 24 & 730 & $(670)$ & 7 & 39 & 3
\end{tabular}

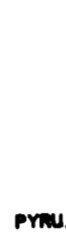

\begin{tabular}{cccccc|c}
36 & 16 & 506 & $(4)$ & $(18)$ & $(63)$ & 2 \\
45 & 20 & 301 & 4 & $(30)$ & 28 & 2 \\
64 & 10 & 345 & $(10)$ & $(30)$ & $(34)$ & 2
\end{tabular}
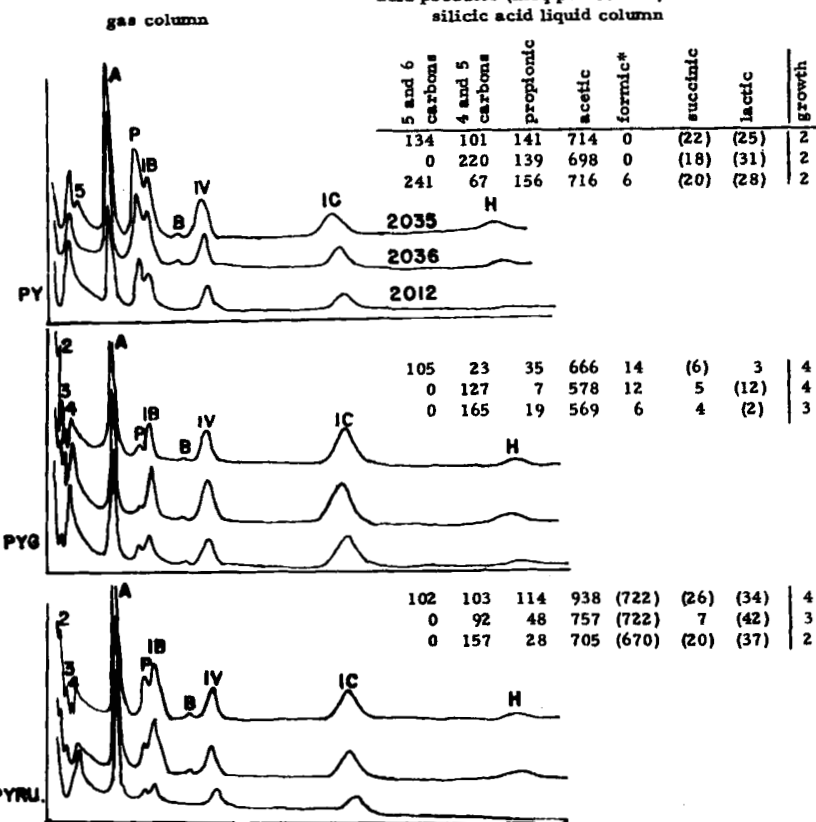

\begin{tabular}{rrrrrr|r|r}
145 & 51 & 31 & 618 & $(10)$ & $(18)$ & $(304)$ & 3 \\
0 & 174 & 47 & 533 & $(3)$ & $(11)$ & $(202)$ & 2
\end{tabular}

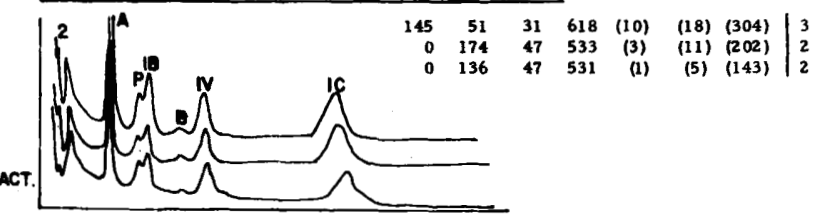

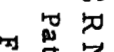
요 空 总 ( ) 忩昜占 욛ㄴ $\rightarrow$ to 6 娄 贻 Z

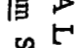
c

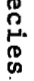


25. Cl. capitovale

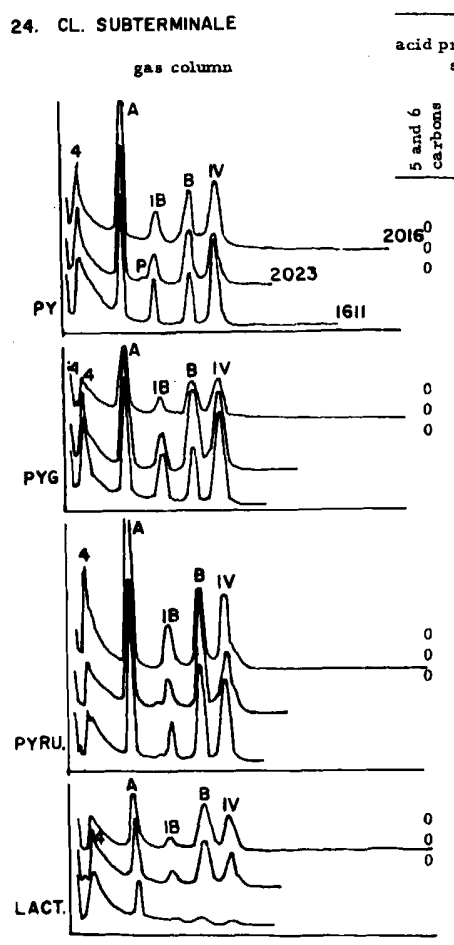

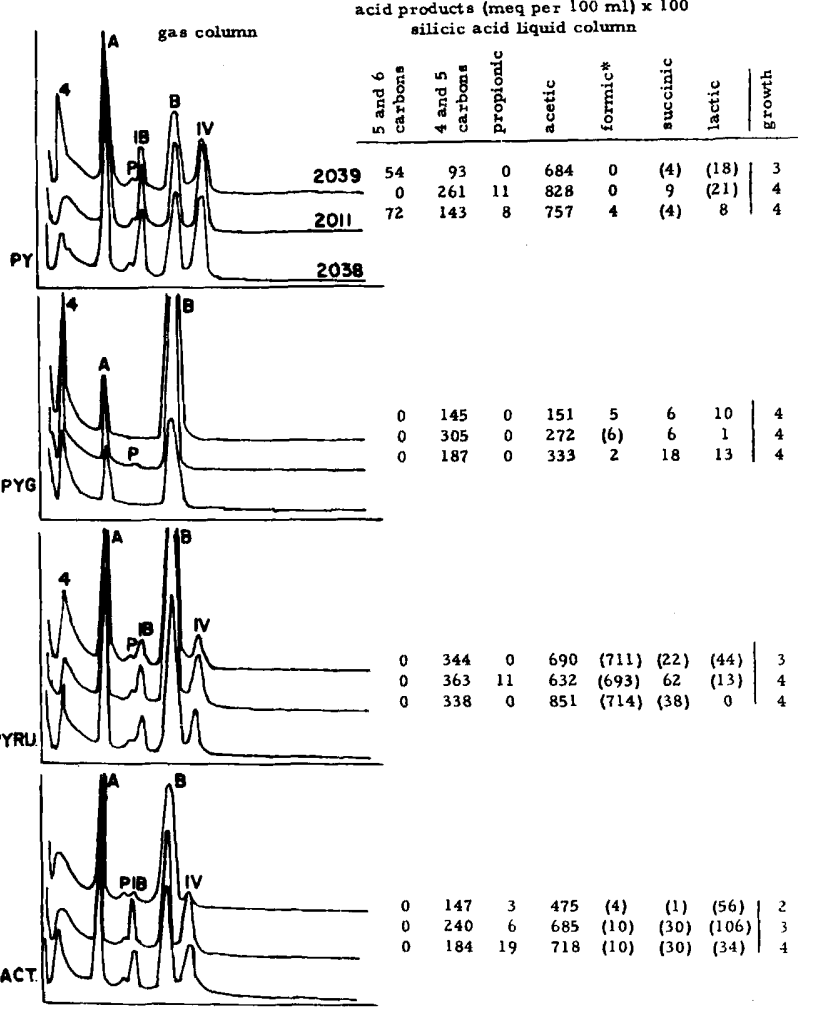

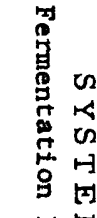

전

哭灵它

$\rightarrow 0$

承吕凹

ㄴㅇㅇ

屯

品简

(1)

贻

空:

自。

की

帘

$\stackrel{4}{9}$ 

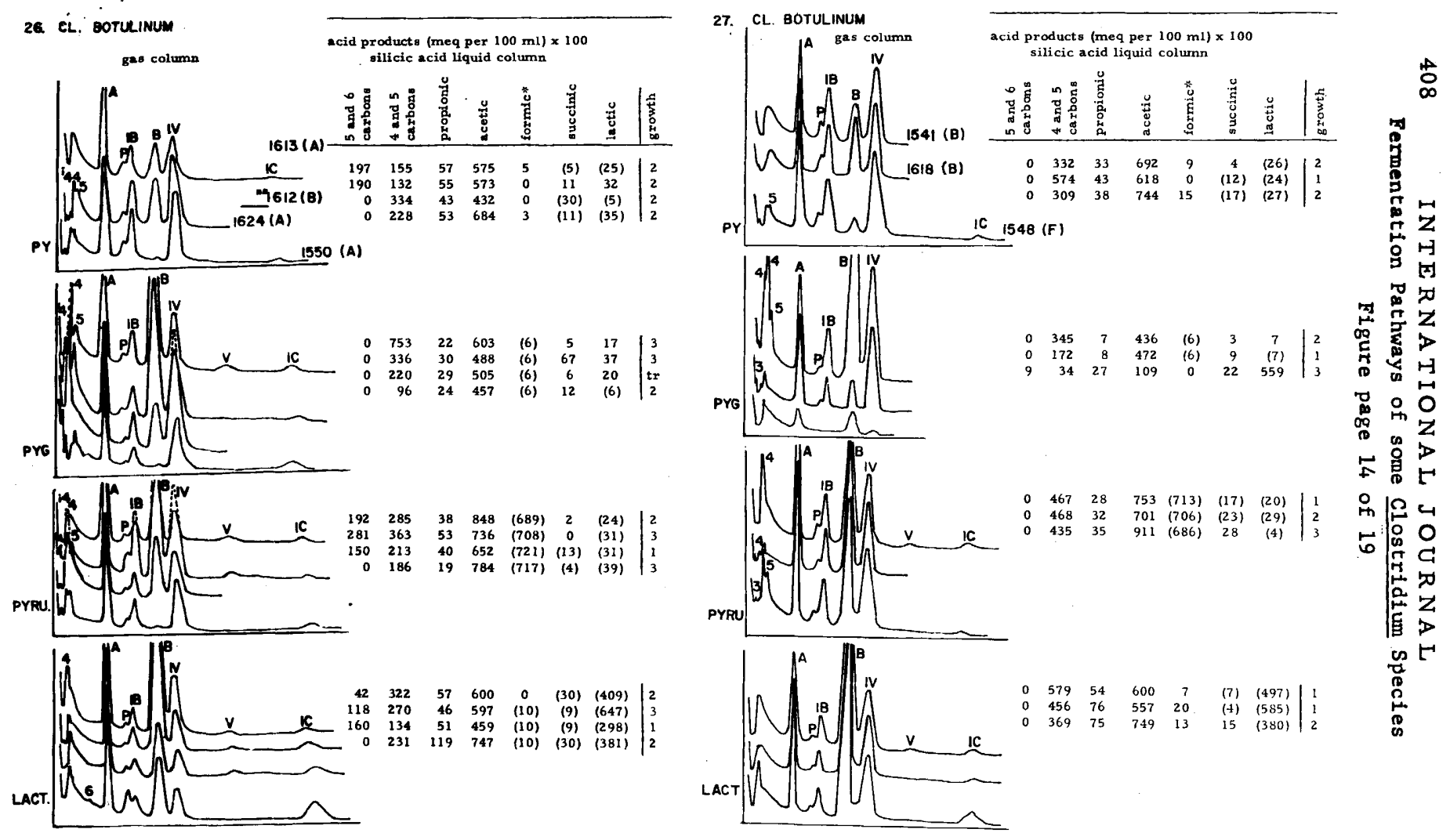


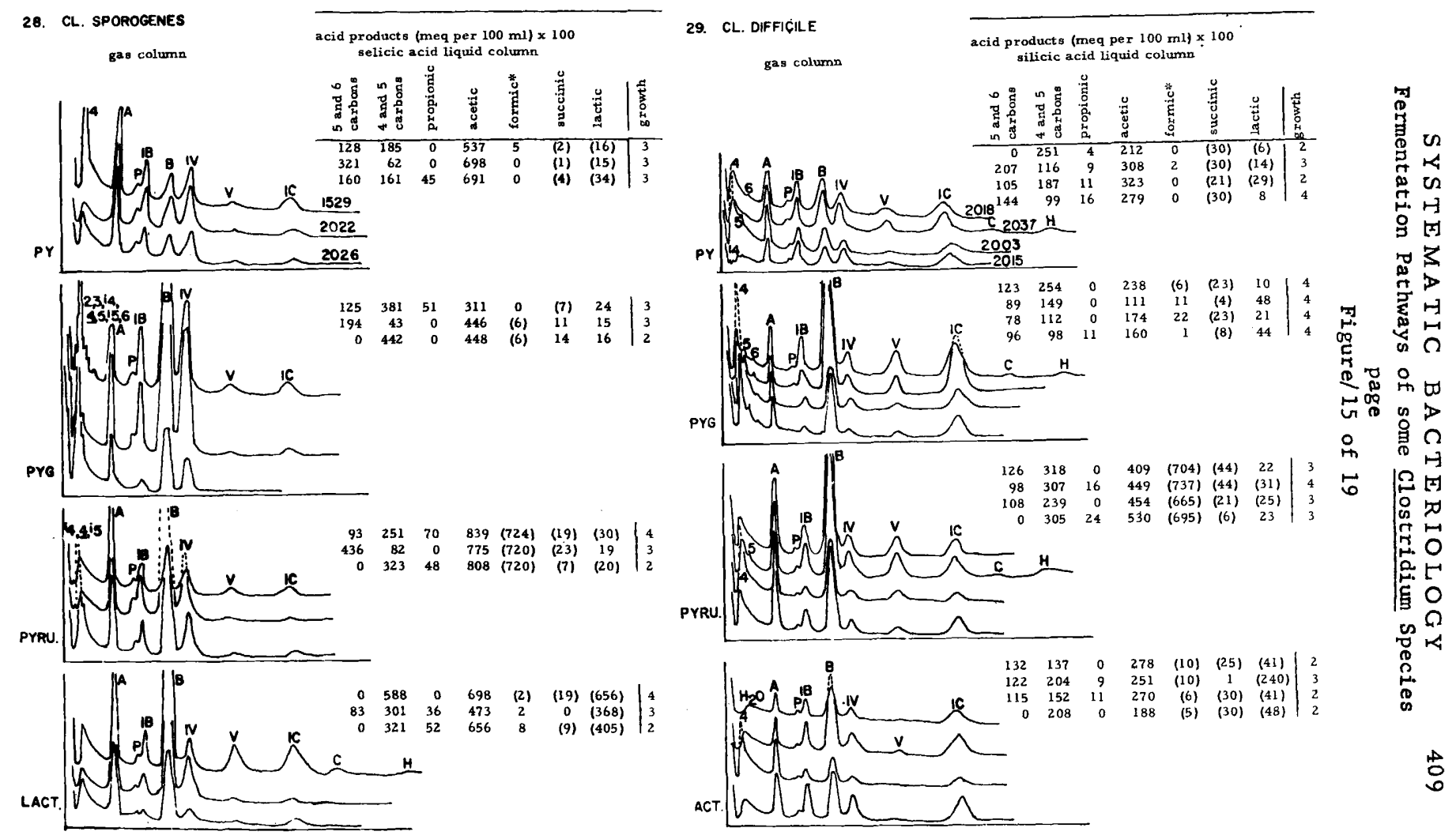


30. CL. SPOROGENES 1529 gas column

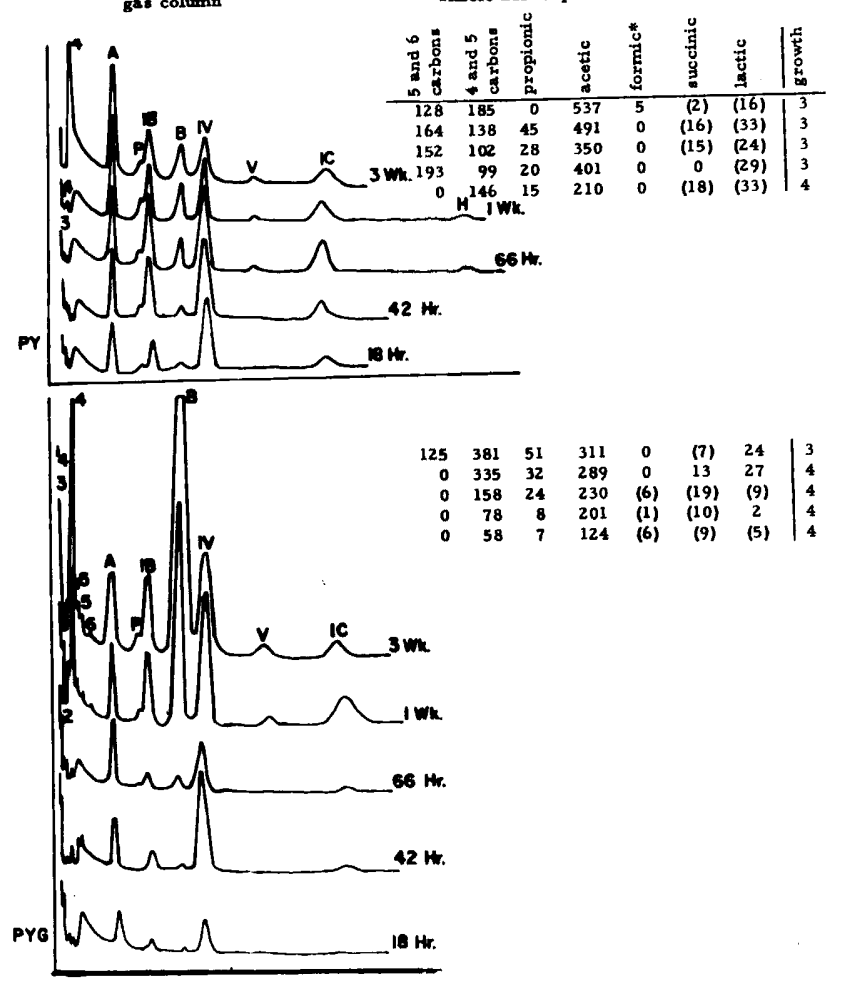

31. CL. SPOROGENES 1529 WITH $\mathrm{CoCO}_{3}$

acid products (meq per $100 \mathrm{ml}$ ) $\times 100$

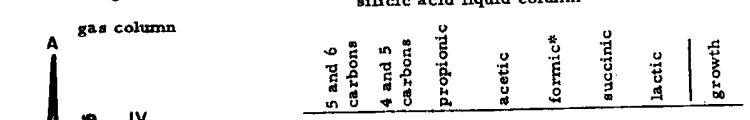

H 3 Wh.
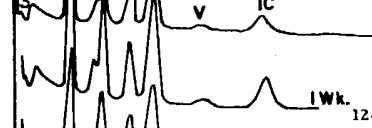

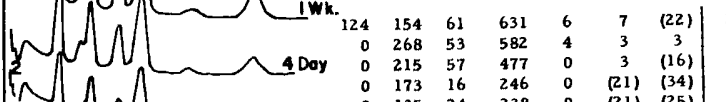

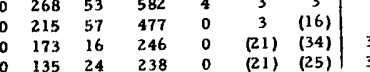
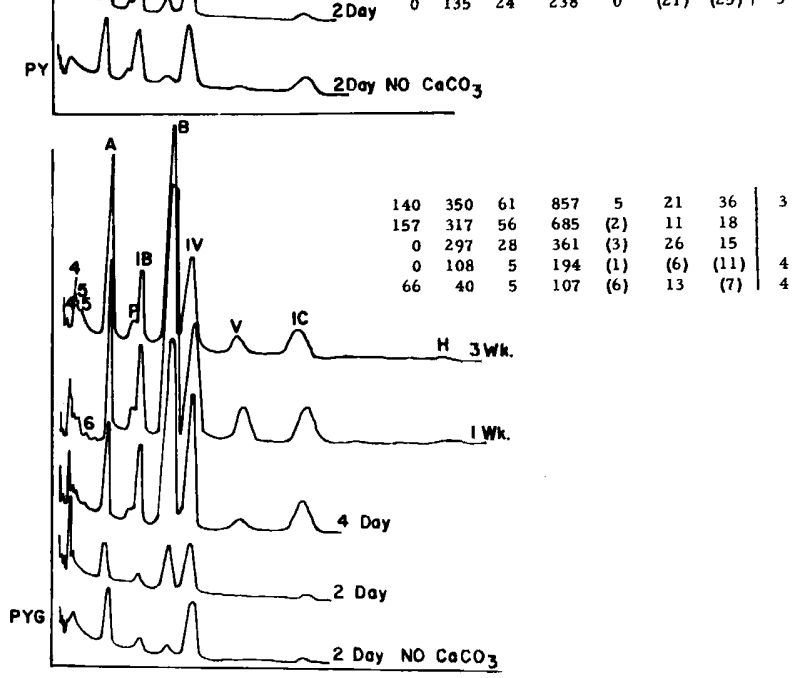

$\stackrel{\leftrightarrow}{\circ}$

(x)

急

两

类 $z$

要闻

西罂

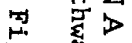

哭

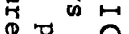
焉品品

另悬点

৮

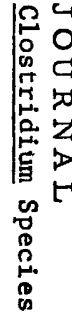


SYSTEMATIC BACTERIOLOGY

Fermentation Pathways of some Clostridium Species

page

- Figure/17 of 19
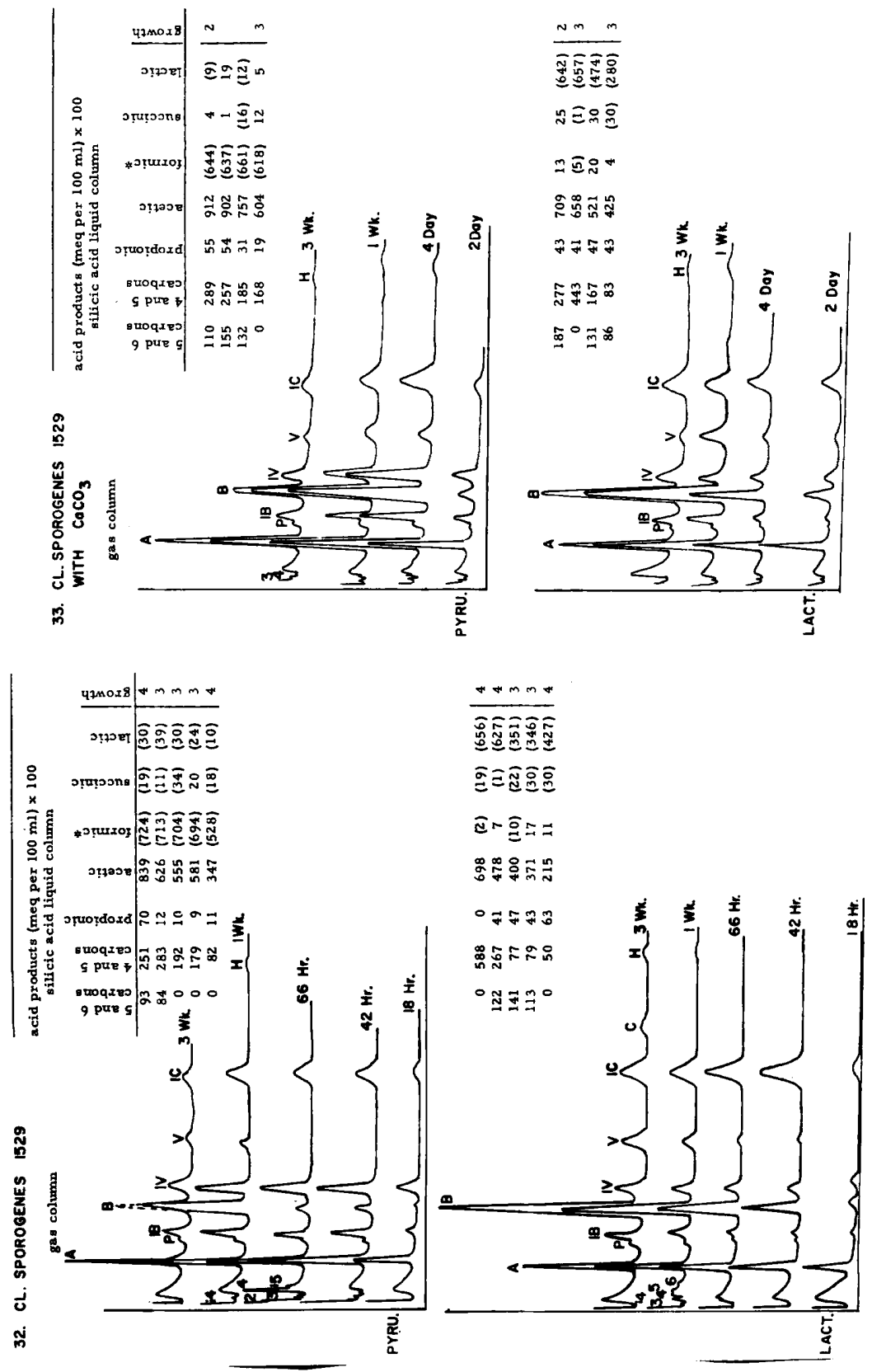
34. CL. NOVYI (A) 1617

gas column
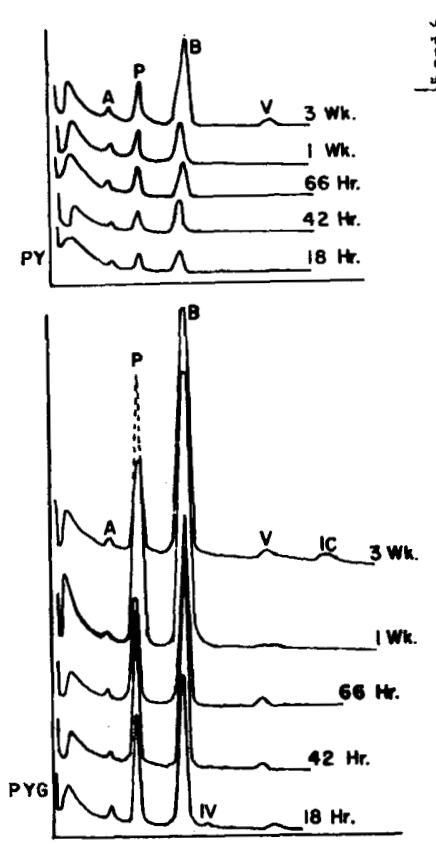

35. CL. NOVYI (A) 1617 WITH $\mathrm{CaCO}_{3}$

gas column
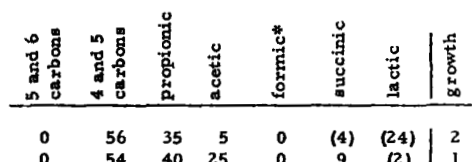

\begin{tabular}{cccccc|c}
54 & 40 & 25 & 0 & 9 & $(2)$ & 1 \\
47 & 50 & 13 & 0 & 3 & $(24)$ & $t r$
\end{tabular}

\begin{tabular}{rrrrrr|r}
47 & 50 & 13 & 0 & 3 & $(24)$ & tr \\
27 & 20 & 8 & 0 & 2 & $(23)$ & 1 \\
24 & 32 & 4 & 0 & 10 & $(29)$ & 2
\end{tabular}
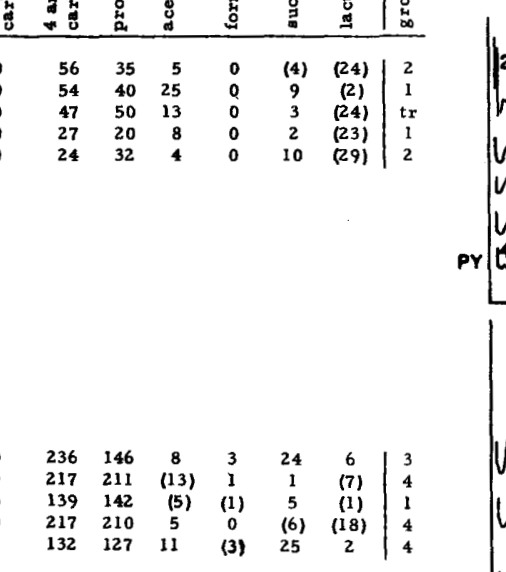

proner

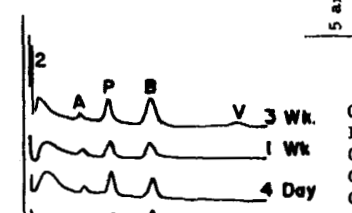

2 Doy

2 Doy $\mathrm{NO} \mathrm{CaCO}_{3}$

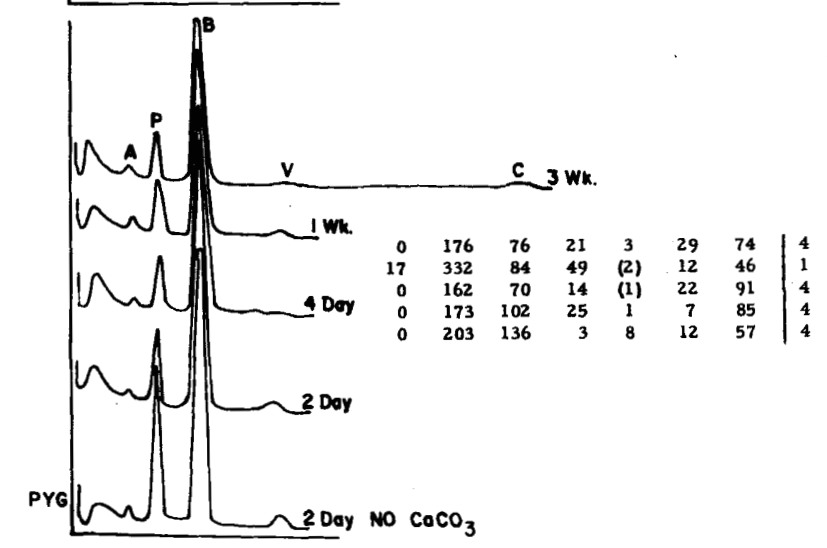

\begin{tabular}{cccccc|c}
33 & 42 & 6 & 0 & 8 & $(33)$ & 3
\end{tabular}

\begin{tabular}{rrrrrr|r}
21 & 28 & 8 & 0 & $(13)$ & $(37)$ & 1 \\
28 & 43 & 15 & 6 & $(2)$ & $(34)$ & 2 \\
18 & 33 & 1 & 0 & 2 & $(29)$ & 2 \\
30 & 21 & 0 & 0 & 10 & $(71$ & 2
\end{tabular}

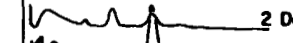

silicic acid liquid column

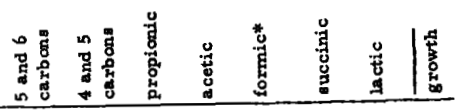

兽

常》

垔 娄

(5)

車实之

용

๘

10

点 0

要

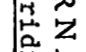

点卢

a 


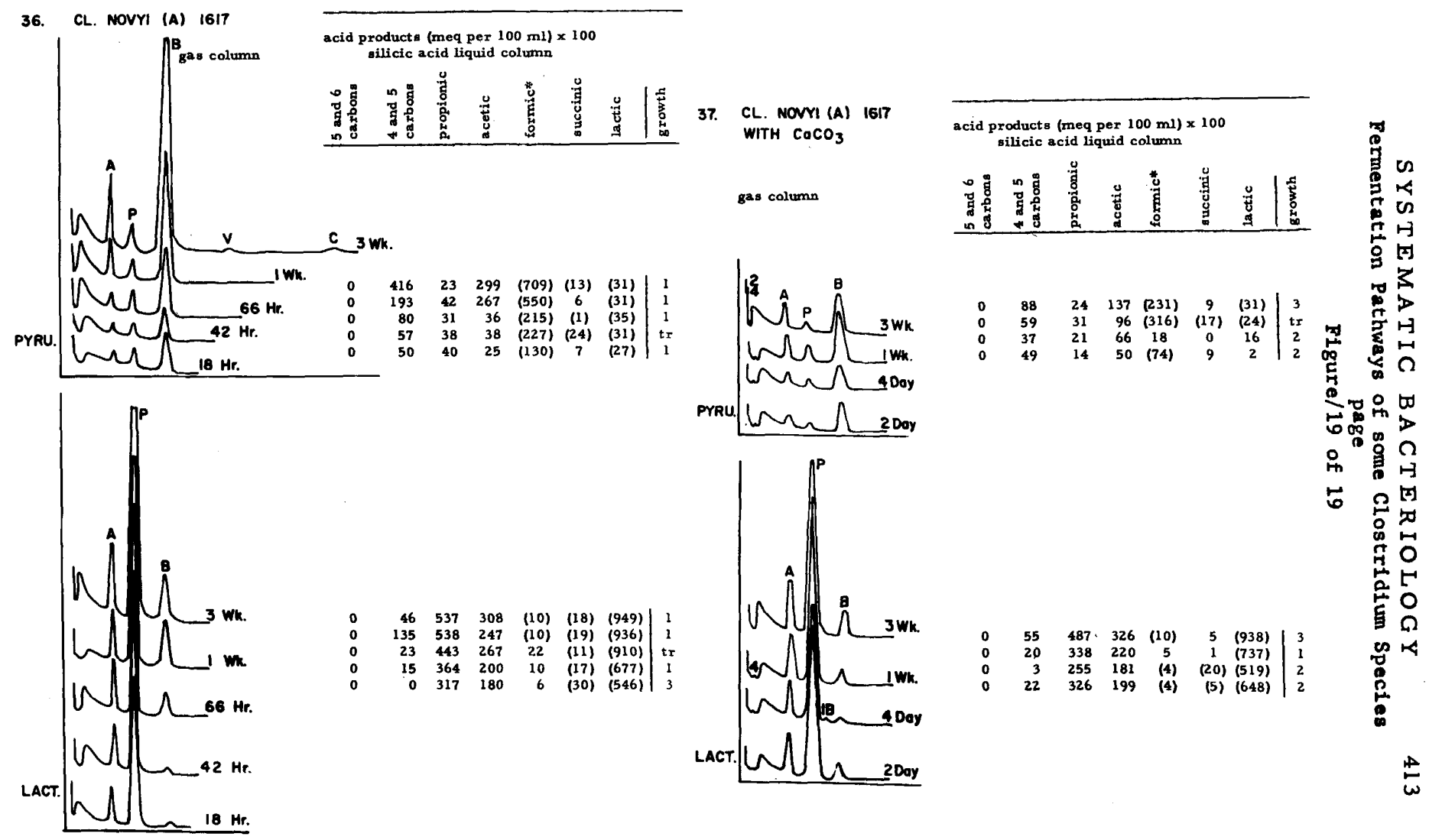


C. botulinum produce a pearly layer on egg yolk agar medium. The isolation of lipase-positive and lipase-negative organisms from a single culture, together with the similar. fermentation patterns of both toxic and "nontoxic C. botulinum type $E, "$ only emphasizes the need for additional characterization of numerous strains of $C$. botulinum $E$ to determine whether characteristics other than toxin production may be used to identify these organisms.

GC Fermentation Group 4 - acetic, propionic, and butyric acids with propionate from lactate - includes $\underline{C}$. novyi $A$ and $B, \underline{C}$. haemolyticum, $\underline{C}$. botulinum $C$ and $D$, and $\underline{C}$. tertium. C. tertium strain 1525 was received from ATCC. Two colony types were isolated from this culture as received and one of them (1565) was subsequently identified as $C$. carnis. It is interesting to note that $\underline{C}$. carnis and $\underline{C}$. ter tium, although very similar in many respects, have distinct fermentation patterns in both pyruvate and lactate. The strains of $\underline{C}$. novyi received from the ATCC were identified by us as type A. This particular strain of type B does not lowe $r$ the $\mathrm{pH}$ in maltose medium, as do most strains of $\mathrm{C}$. novyi $B$.

GC Fermentation Group 5 - acetic, propionic, and butyric acids with butanol - includes C. tetani. C. tetani is the only species we have observed which produces large amounts of butanol, in addition to ethanol, in all of the media tested.

GC Fermentation Group 6 - acetic, propionic, isobutyric, isovaleric, isocaproic acids - includes $\mathrm{C}$. sordellii and $\mathrm{C}$. bifermentans. As might be expected, strains of $\underline{C}$. bifermentans and C. sordellii produce very similar acid and alcohol products. They differ in that trace amounts of heptanoic acid are produced by all strains of $\underline{C}$. bifermentans which we have examined.

GC Fermentation Group 7 - acetic, propionic, isobutyric, butyric, isovaleric acids - includes $\underline{C}$. subterminale and $\underline{\text { C. }}$ capitovale. These two organisms produce fermentation patterns which differ in that glucose inhibits the production of isobutyric and isovaleric acid by strains of $\underline{\mathrm{C}}$. capitovale.

GC Fermentation Group 8 - acetic, propionic, isobutyric, butyric, isovaleric, isocaproic acids - includes $\underline{C}$. difficile, 
C. sporogenes, and the proteolytic strains of $\underline{C}$. botulinum $A$, $B$, and $F$. This complex pattern includes as many as 16 acid and alcohol products detected under the present conditions.

We feel that the analysis of these fermentation products of cell metabolism is useful for both taxonomic and diagnostic identification of organisms. This concept is not new, for results of our analyses supplement and often confirm many findings by $A-R$. Prévot and other investigators. Fermentation patterns appear to be stable characteristics of an organism. The patterns which we have seen from many species of organisms represent an important number of enzymes in the metabolic systems of cells. Information about fermentation activities often contributes substantially to the determination of the potential role of an organism in nature. The patterns agree exceptionally well among strains identified by other tests which have been found by previous inves tigators to provide stable diagnostic characteristics for species or groups of species. If this relationship holds true, such information should prove most useful in characterization of unidentified or poorly characterized cultures.

\section{ACKNOW LEDGMENTS}

The authors wich to thank W. B. Gross for the photographic preparations and Alice B. Nicely, Mary D. Coleman, Ann S. Ammons, and Ann C. Mitchell for their valuable assistance in the analytical work.

\section{LITERATURE CITED}

Bruno, C.F. and W.E.C. Moore. 1962. Fate of lactic acid in rumen ingesta. Jour. Dairy Sci. 45:109-115.

Moore, W.E.C. and E. P. Cato. 1965. Synonymy of Eubacterium limosum and Butyribacterium rettgeri: Butyribacterium limosum comb. nov. Int. Bull. Bact. Nomen. and Taxon. 15:69-80.

Smith, L. DS. 1953. The essential characteristics of the species Clostridium hemolyticum. Jour. Bact. 65:222. 
